\title{
MR spectroscopy in pediatric neuroradiology
}

\author{
Roberto Liserre $^{1 \wedge}$, Lorenzo Pinelli ${ }^{1}$, Roberto Gasparotti ${ }^{2}$ \\ ${ }^{1}$ Department of Radiology, Neuroradiology Unit, ASST Spedali Civili University Hospital, Brescia, Italy; ${ }^{2}$ Neuroradiology Unit, Department of \\ Medical-Surgical Specialties, Radiological Sciences and Public Health, University of Brescia, Brescia, Italy \\ Contributions: (I) Conception and design: R Liserre; (II) Administrative support: R Liserre, L Pinelli; (III) Provision of study materials or patients: R \\ Liserre, L Pinelli; (IV) Collection and assembly of data: R Liserre, L Pinelli; (V) Data analysis and interpretation: R Liserre; (VI) Manuscript writing: \\ All authors; (VII) Final approval of manuscript: All authors. \\ Correspondence to: Roberto Liserre. Neuroradiology Unit, ASST Spedali Civili di Brescia, 25123 Brescia, Italy. Email: roberto.liserre@asst-spedalicivili.it.
}

\begin{abstract}
Magnetic resonance spectroscopy (MRS), being able to identify and measure some brain components (metabolites) in pathologic lesions and in normal-appearing tissue, offers a valuable additional diagnostic tool to assess several pediatric neurological diseases. In this review we will illustrate the basic principles and clinical applications of brain proton $\left(\mathrm{H}^{1}\right.$; hydrogen) MRS $\left(\mathrm{H}^{1} \mathrm{MRS}\right)$, by now the only MRS method widely available in clinical practice. Performing $\mathrm{H}^{1} \mathrm{MRS}$ in the brain is inherently less complicated than in other tissues (e.g., liver, muscle), in which spectra are heavily affected by magnetic field inhomogeneities, respiration artifacts, and dominating signals from the surrounding adipose tissues. $\mathrm{H}^{1} \mathrm{MRS}$ in pediatric neuroradiology has some advantages over acquisitions in adults (lack of motion due to children sedation and lack of brain iron deposition allow optimal results), but it requires a deep knowledge of pediatric pathologies and familiarity with the developmental changes in spectral patterns, particularly occurring in the first two years of life. Examples from our database, obtained mainly from a 1.5 Tesla clinical scanner in a time span of 15 years, will demonstrate the efficacy of $\mathrm{H}^{1} \mathrm{MRS}$ in the diagnosis of a wide range of selected pediatric pathologies, like brain tumors, infections, neonatal hypoxic-ischemic encephalopathy, metabolic and white matter disorders.
\end{abstract}

Keywords: Brain disorders; magnetic resonance spectroscopy (MRS); pediatrics

Submitted Dec 14, 2020. Accepted for publication Feb 25, 2021.

doi: $10.21037 / \mathrm{tp}-20-445$

View this article at: http://dx.doi.org/10.21037/tp-20-445

\section{Introduction}

Most clinical magnetic resonance (MR) scanners currently allow $\mathrm{H}^{1} \mathrm{MRS}$ in shorter acquisition times than in past decades and relatively easy automated post-processing methods are available (1). $\mathrm{H}^{1}$ MRS complements the information provided by conventional MRI enabling tissue characterization on a biochemical level and may add clinically relevant data for selected groups of pediatric cerebral and systemic diseases: $\mathrm{H}^{1} \mathrm{MRS}$ can discriminate different kind of injuries with similar MRI pattern or identify metabolic abnormalities preceding structural changes.

We will describe only the most commonly used acquisition and post-processing methods at 1.5 and 3 Tesla (T), thus excluding the more complex and less available techniques, like editing sequences (2), multi-proton MRS (e.g., carbon-13, fluorine-19 and phosphorus-31 spectroscopy) (3) and ultra-high field Spectroscopy (7T and more) (4).

In most cases, $3 \mathrm{~T}$ scanners compared to $1.5 \mathrm{~T}$ magnets produce better quality spectra because of increased signal to noise ratio (SNR) and chemical shift dispersion, but there are exceptions to this rule, which will be briefly reviewed.

$\wedge$ ORCID: 0000-0003-1536-0183. 


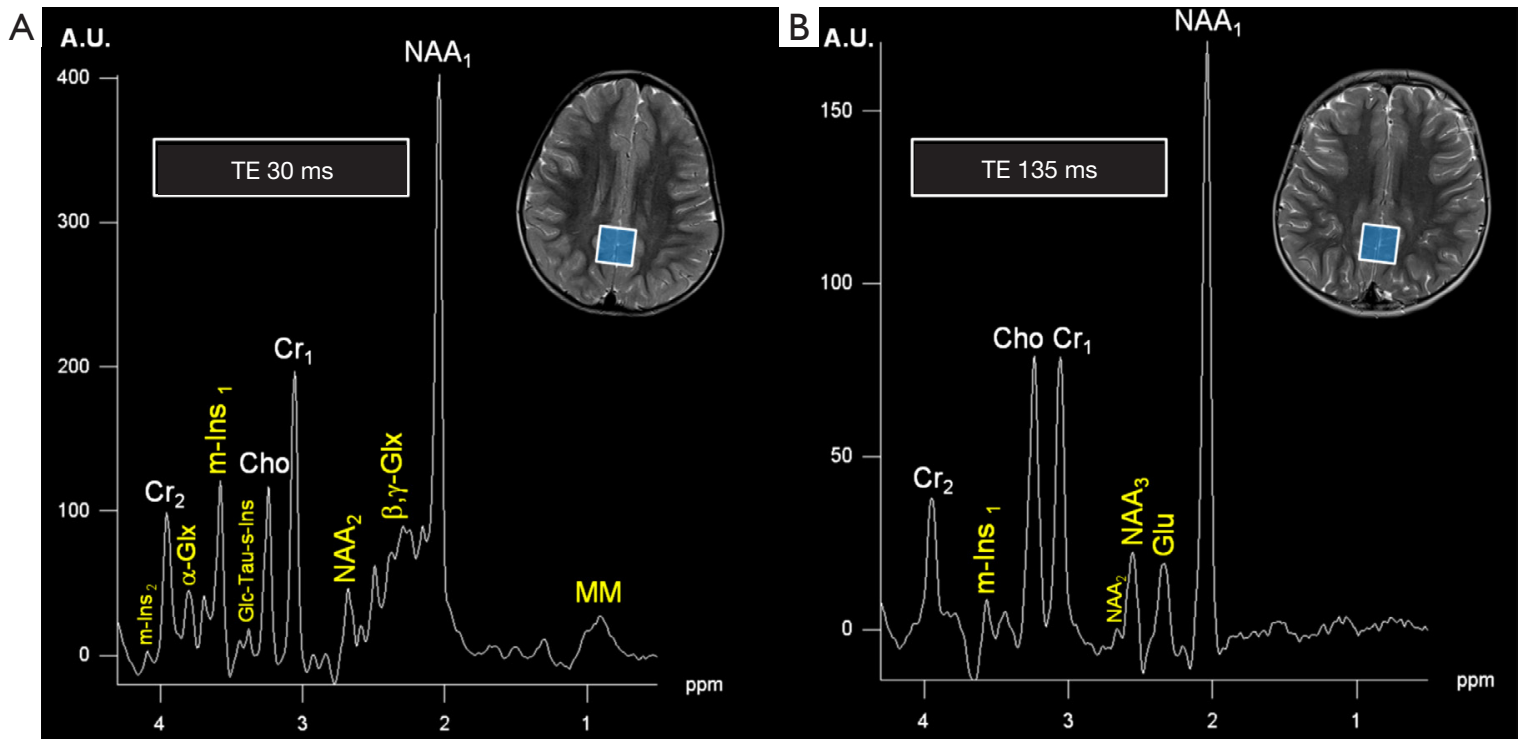

Figure 1 "Standard" $(2 \mathrm{~cm} \times 2 \mathrm{~cm} \times 2 \mathrm{~cm})$ gray matter $1.5 \mathrm{~T}$ single voxel spectra acquired from posterior cingulum in healthy subjects with short echo time (TE) in a 6-year-old female (A) and with intermediate TE in a 4-year-old male (B) ("adult pattern"). In (A) (short TE) the four main singlets $\left(\mathrm{Cr}_{2}\right.$, tCho, $\left.\mathrm{Cr}_{1}, \mathrm{NAA}_{1}\right)$ are labeled in white; a prominent $\mathrm{m}$-Ins $\mathrm{I}_{1}$ signal and many other smaller peaks are visible: the first one on the left at 4.05-4.06 ppm (m-Ins $)_{2}$ is an index of optimal spectral quality with adequate water suppression; $\beta, \gamma-\mathrm{Glx}$ peaks in the 2.1-2.5 ppm range and Glc-Tau-s-Ins in the 3.35-3.45 ppm range often require advanced post-processing for a correct assignation. In (B) (intermediate TE) in addition to the main singlets $\left(\mathrm{Cr}_{2}, \mathrm{tCho}, \mathrm{Cr}_{1}, \mathrm{NAA}_{1}\right)$, physiological smaller peaks of $\mathrm{m}_{-} \mathrm{Ins}_{1}, \mathrm{NAA}_{2}, \mathrm{NAA}_{3}$, and $\mathrm{Glu}_{\mathrm{u}}$ identifiable; increased T2-weighting at this TE causes a disproportionate amount of signal loss for Cr compared to tCho, therefore, tCho/ Cr ratio is "artifactually" elevated. Acronyms and abbreviations are shown in Appendix 1.

\section{Theoretical background of $\mathbf{H}^{1}$ MRS}

Conventional MRI and $\mathrm{H}^{1}$ MRS rely on the same physical principles to collect signal: while MRI employs hydrogen nuclei to create images, $\mathrm{H}^{1} \mathrm{MRS}$ analyzes the signal of hydrogen attached to other molecules. MRI creates anatomical maps using only a single peak (water); $\mathrm{H}^{1} \mathrm{MRS}$ returns a plot (with peak amplitudes on the $y$-axis compared with definite frequencies on the $\mathrm{x}$-axis) representing hydrogen nuclei in different chemical environments (Figure 1) (5).

The $\mathrm{x}$-axis of the spectrum is also called "chemical shift axis" and shows the "frequency shift" (i.e., the difference in the resonant frequency) of a proton relative to a universally accepted reference compound: TetraMethylSilane (TMS) at 0 "parts per million" (ppm). The chemical shift scale increases from right to left in plotted spectra. Usually, the spectral fitting range is set between 0.5 and $4.1 \mathrm{ppm}$. The ppm scale has the advantage over the Hertz $(\mathrm{Hz})$ scale to remain constant independently from magnetic field strength, allowing data comparison between different MR scanners. Each metabolite is identified by one or more peaks with peculiar resonance frequencies (i.e., positions along the chemical shift axis) and definite shapes ("singlets", "doublets", "multiplets"), widths and heights. The y-axis determines the signal intensity: the area under the resonance peak is proportional to the metabolite concentration and to the number of protons contributing to the signal (6). Protons have different chemical shift unless they are "chemically equivalent" (i.e., they have identical chemical reactions): for example, all the 3 protons of the methyl $\left(\mathrm{CH}_{3}\right)$ groups both in creatine $(\mathrm{Cr})$ and $\mathrm{N}$-acetyl-aspartate (NAA) molecules will resonate at the same position (3.03 and $2.02 \mathrm{ppm}$ respectively) on the $\mathrm{x}$-axis, therefore their signal will be additive in each resulting "singlet" (7). The spectroscopic fingerprint of each neurochemical will be easily identified only if its concentration or its number of equivalent protons will be enough and/or if the number of other overlapping metabolite peaks will be very low.

"J-coupling" ("scalar coupling", "spin-spin coupling") is an indirect interaction between magnetic nuclei which are chemically bonded to one another: it is a molecular 


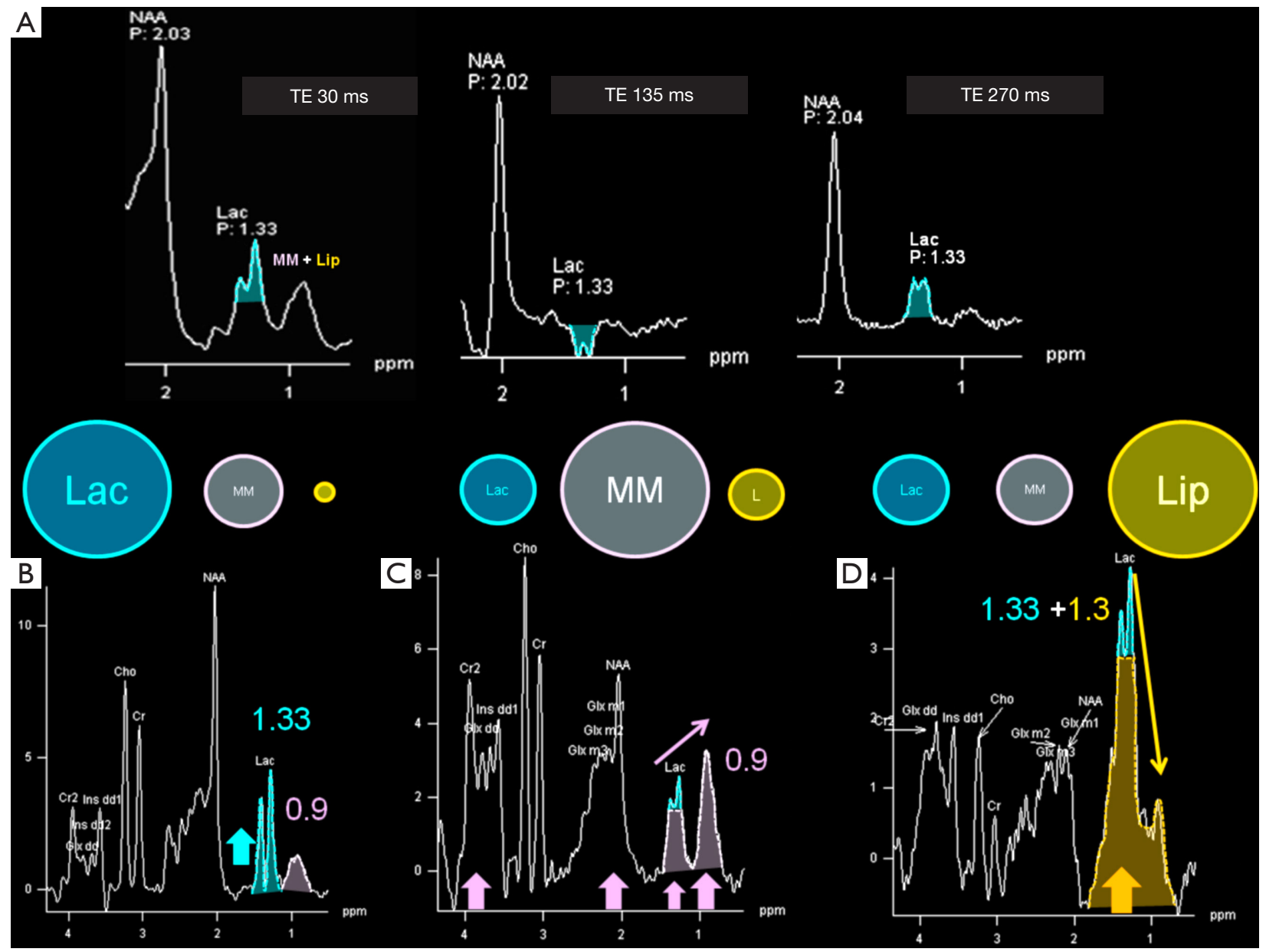

Figure 2 Top row (A): three spectra acquired at $1.5 \mathrm{~T}$ in a neonate with moderate HIE at short (30 ms), intermediate (135 ms), and long (270 ms) echo times, for lactate (Lac, labeled in light blue) confirmation; only at intermediate TE the phase of the $\mathrm{CH}_{3}$ doublet of $\mathrm{Lac}$ is inverted below the baseline. At intermediate and long TE, mobile lipids (Lip) and macromolecules (MM) signals are nulled. Bottom row: examples of different contributions of pathological Lac, MM (labeled in pink) and Lip (labeled in yellow) signals in the 0.8-1.4 ppm range in three short TE spectra acquired at $1.5 \mathrm{~T}$ in infants, respectively with mitochondrial encephalopathy (B), extensive demyelination and atrophy of unknown origin (C) and extensive necrosis in sulfite oxidase deficiency (D). In (B) only a prominent Lac peak and physiological MM are detected; in (C) the contribution of physiological and pathological MM (major peak at $0.9 \mathrm{ppm}$ ) is predominant: broad resonances lead to overestimation not only of Lac, but also of NAA and $\beta, \gamma-\mathrm{Glx}$ (in the $2-2.5 \mathrm{ppm}$ range) and of $\mathrm{Cr}_{2}, \alpha-\mathrm{Glx}$ and $\mathrm{m}$-Ins (in the $3.5-4 \mathrm{ppm}$ range); in (D) the spectra is dominated by the huge Lip resonance at $1.3 \mathrm{ppm}$ with lesser pathological MM contribution; also an overestimation of Lac (labeled in light blue), $\beta, \gamma-\mathrm{Glx}, \mathrm{m}$-Ins, $\alpha$-Glx and $\mathrm{Cr}_{2}$ occurs. Acronyms and abbreviations are shown in Appendix 1.

property that heavily affects spectra interpretation, but that can also be exploited to recognize some metabolites peaks. The appearance of the spectrum arising from coupled spins depends on the magnitude of the coupling constant ("J", measured in $\mathrm{Hz}$ ) and becomes more complex as the number and types of coupled nuclei increase (8). In the simplest condition, each signal is split into two lines (separated by $\mathrm{J})$, called a "doublet"; the chemical shift of each signal is exactly at the midpoint of each doublet (e.g., the lactate doublet is centered at $1.33 \mathrm{ppm}$, with a $\mathrm{J}$ value given in the range of 6.9-7.3 Hz) (9) (Figure 2). On the other hand, peaks identification is difficult when the signal splitting is more complicated: for instance, glutamate, glutamine, and $\gamma$-aminobutyric acid (GABA) "multiplets" significantly overlap (see below).

Conventional MRI exploits the high-water concentration 
in the brain to obtain diagnostic images in very short times. In $\mathrm{H}^{1} \mathrm{MRS}$, on the contrary, water resonance has to be suppressed (the residual $\mathrm{H}_{2} \mathrm{O}$ signal is visible beyond the extreme left side of the spectrum, at $4.7 \mathrm{ppm}$ ) (Figure 3) to identify in vivo the relatively few metabolites of interest that are in the millimolar range: only small and mobile chemicals with concentrations of at least $\sim 0.5 \mathrm{mmol} / \mathrm{kg}$ tissue can be detected. For this reason large and immobile macromolecules ("MM": e.g., myelin, proteins, nucleic acids), most neurotransmitters and many other clinically valuable metabolites cannot be displayed (10). The usually low concentrations of the majority of the detectable metabolites require specific strategies to increase SNR (e.g., long acquisition times) and limits $\mathrm{H}^{1} \mathrm{MRS}$ analyses to volumes of interest (voxels) of at least $1-1.5 \mathrm{~cm}^{3}$.

\section{$\mathbf{H}^{1}$ MRS protocols to be used}

In the last 30 years, lots of sophisticated and often timeconsuming $\mathrm{H}^{1}$ MRS data acquisition methods have been developed for research. However, the two main sequences used in clinical practice are PRESS (Point-REsolved Spectroscopy Sequence) and STEAM (Stimulated Echo Acquisition Mode). Although STEAM can allow a shorter minimum TE, PRESS is usually the preferred sequence because of its higher SNR (11). More recently two-dimensional J-resolved localized and semi-localized by adiabatic selective refocusing sequences (LASER and semi-LASER) have been introduced to reduce chemical shift artifacts and additional artifactual peaks at 3 Tesla (12).

Both sequences and acquisition parameters (echo time, repetition time, number of excitations) influence the visualization of metabolite peaks. For the common dilemmas of the choice between single-voxel MRS and multi-voxel (CSI) or between short, intermediate, and long echo times there are no single correct answers. Understanding the artifacts and limitations of $\mathrm{H}^{1} \mathrm{MRS}$, pulse sequences and how the metabolite peaks are affected by parameters change is essential for data interpretation.

\section{Echo time choice}

The variation of the most important parameter, echo time (TE), influences the T2-weighting of the MRS sequence and it is often used to confirm peak assignment in the $\mathrm{H}^{1}$ spectrum. Proceeding from short to intermediate to long TEs, metabolites signal decreases, but outer volume water,
MM and lipids are also progressively attenuated, eddy currents fade away, and as a result, singlets (e.g., $\mathrm{NAA}_{1}, \mathrm{Cr}_{1}$, see below) dominate the spectrum.

Short TE (20-40 ms, usually $30 \mathrm{~ms}$ ) sequences are useful in demonstrating those metabolites with a short $\mathrm{T} 2$ decay time, like myo-Inositol (m-Ins), Glutamine/Glutamate $($ Gln + Glu = "Glx") (Figure 1A), and also some amino acids (alanine, "Ala"), lactate ("Lac") and lipids ("Lip"), although they overlap in the 1.2-1.5 ppm range (Figure 2).

Clinical indication should determine the choice of TE. For example, in the characterization of pediatric posterior fossa tumors, short TE $\mathrm{H}^{1}$ MRS is recommended to identify those metabolites usually detectable only with short TE, such as taurine (11).

Intermediate echo time (97-144 ms) (Figure 1B) is the preferred TE in clinical practice for its simplified appearance because of less baseline distortion compared with short TE and robust information given on only few metabolites (i.e., NAA, tCho, Cr, Lac). In particular, J-modulation/inversion of the Lac and Ala doublet peaks with a TE in the 135-144 ms range (Figure $2 A$ ) allows the differentiation from lipids at $1.5 \mathrm{~T}$. Of note, a recently optimized PRESS sequence with a $\mathrm{TE}$ of $97 \mathrm{~ms}$ is used for identification of the oncometabolite 2-hydroxyglutarate ("2HG", Figure 4) in "IDH1/2 mutant" glioma at $3 \mathrm{~T}(13,14)$.

In long echo time sequences (longer than $144 \mathrm{~ms}$, usually 270-288 ms) the T2 decay of metabolites determines significant loss of signal and, therefore, higher acquisition times are needed to compensate the lower SNR. In clinical practice a long TE MRS is performed for a more accurate depiction of lactate levels at $3 \mathrm{~T}$ (15) or to obtain a full suppression of "unwanted" peaks at 1.5T: e.g., lipids (for Lac, Ala, and other amino acids identification) (Figure 2A) and myo-Inositol (for better glycine assessment, see below).

\section{Single voxel spectroscopy (SVS) vs. chemical shift/MRS imaging (CSI, MRSI)}

Generally speaking, single voxel short echo times $\mathrm{H}^{1} \mathrm{MRS}$ (usually PRESS, $30 \mathrm{~ms}$ TE) ensures higher signal, higher quality with more metabolites detected, less artifacts and acceptable acquisition times $(2-3$ minutes at $3 \mathrm{~T}$, 3-4 minutes at $1.5 \mathrm{~T}$ ); it also allows a simple absolute quantification method by acquiring the same voxel without water suppression for a $\mathrm{H}_{2} \mathrm{O}$ reference data set (only a few seconds more are needed). The voxel size in SVS should be set as bigger as possible to obtain sufficient SNR without 

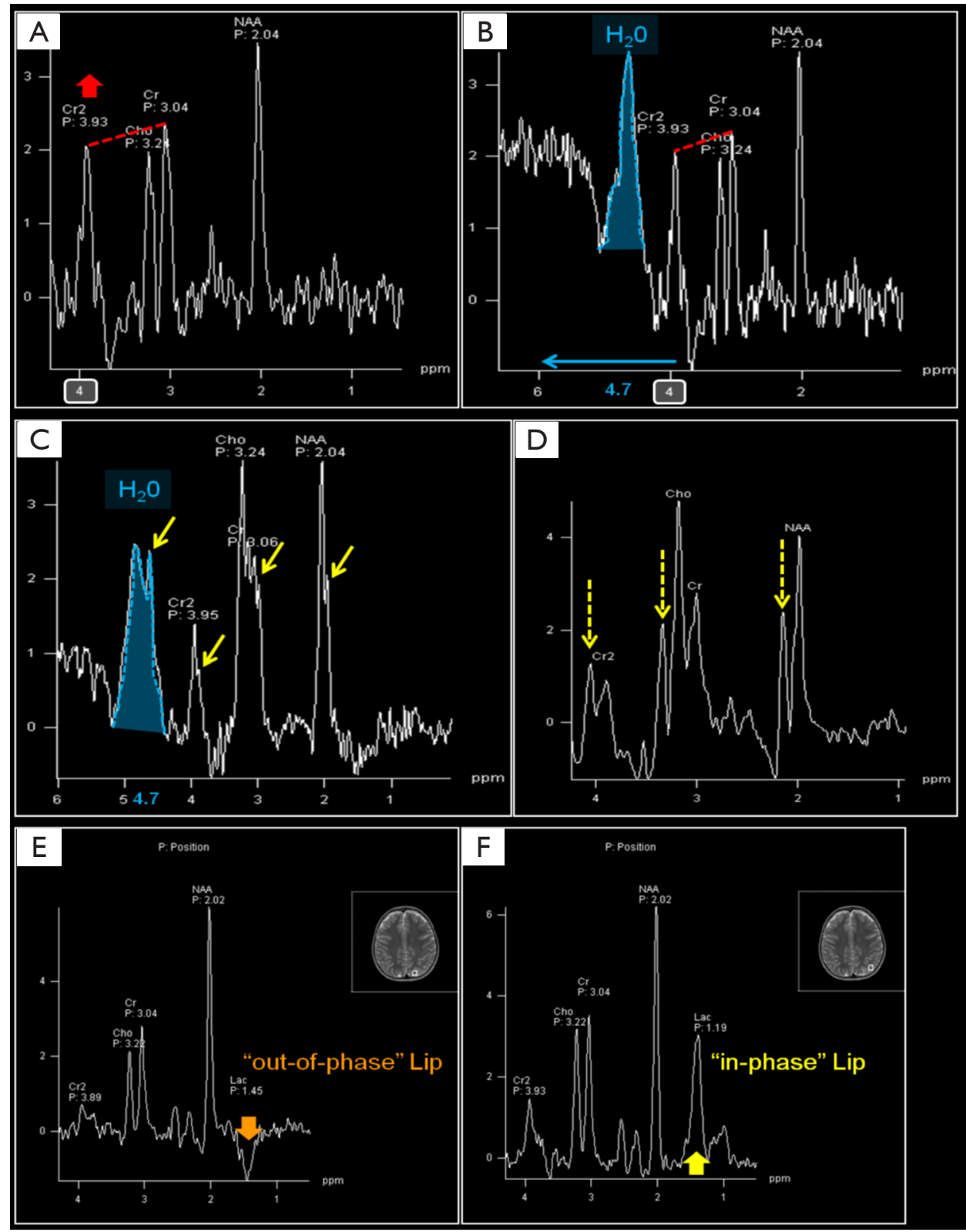

Figure $3 \mathrm{H}^{1} \mathrm{MRS}$ artifacts at intermediate TE $(135 \mathrm{~ms}, 1.5 \mathrm{~T})$. Spectrum of a 5-year-old child with mild psychomotor retardation in (A) characterized by a noisy fluctuating baseline with an abnormally high $\mathrm{Cr}_{2}$ peak at 3.93 ppm (red thick arrow, red dotted lines); motion artifacts cause increased linewidths, overall frequency shifts and decreased quality of water suppression: "broadening" the spectrum to the left to examine the 6 to $4 \mathrm{ppm}$ interval (B) reveals bad water suppression (peak at $4.7 \mathrm{ppm}$ labeled in blue) as the cause of $\mathrm{Cr}_{2}$ overestimation and of substantial loss of information, particularly in the 3.5-4 ppm range. In case (C), gross bulk motion of a 5-month-old infant with epilepsy generates a doubling of all singlet peaks (thin yellow arrows) and an overlap of $\mathrm{Cr}_{1}$ and $\mathrm{tCho}$ resonances. "Spurious" radio frequency signals led to 3 "ghost" peaks in the spectrum of a 2 months preterm infant (dotted yellow arrows in D): ghost signals are partially "out-of-phase" (below the baseline) and don't have to be mistaken for additional pathologic peaks. In (E) and (F) outer volume Lip contaminations in a 13-year-old autistic boy are shown: Lip signals from the adjacent left parietal scalp are characterized in (E) by a different phase than the signal from within the VOI; this "out-of-phase" Lip signal (thick orange arrow) could be mistaken for an inverted Lac signal looking at the automatic peak assignment. Inspection of the contiguous voxel (F), showing the more classical "in-phase" signal seen at 1.3 (thick yellow arrow) and 0.9 ppm, confirms that selection pulses have excited also the spins outside the targeted VOI. Acronyms and abbreviations are shown in Appendix 1. 

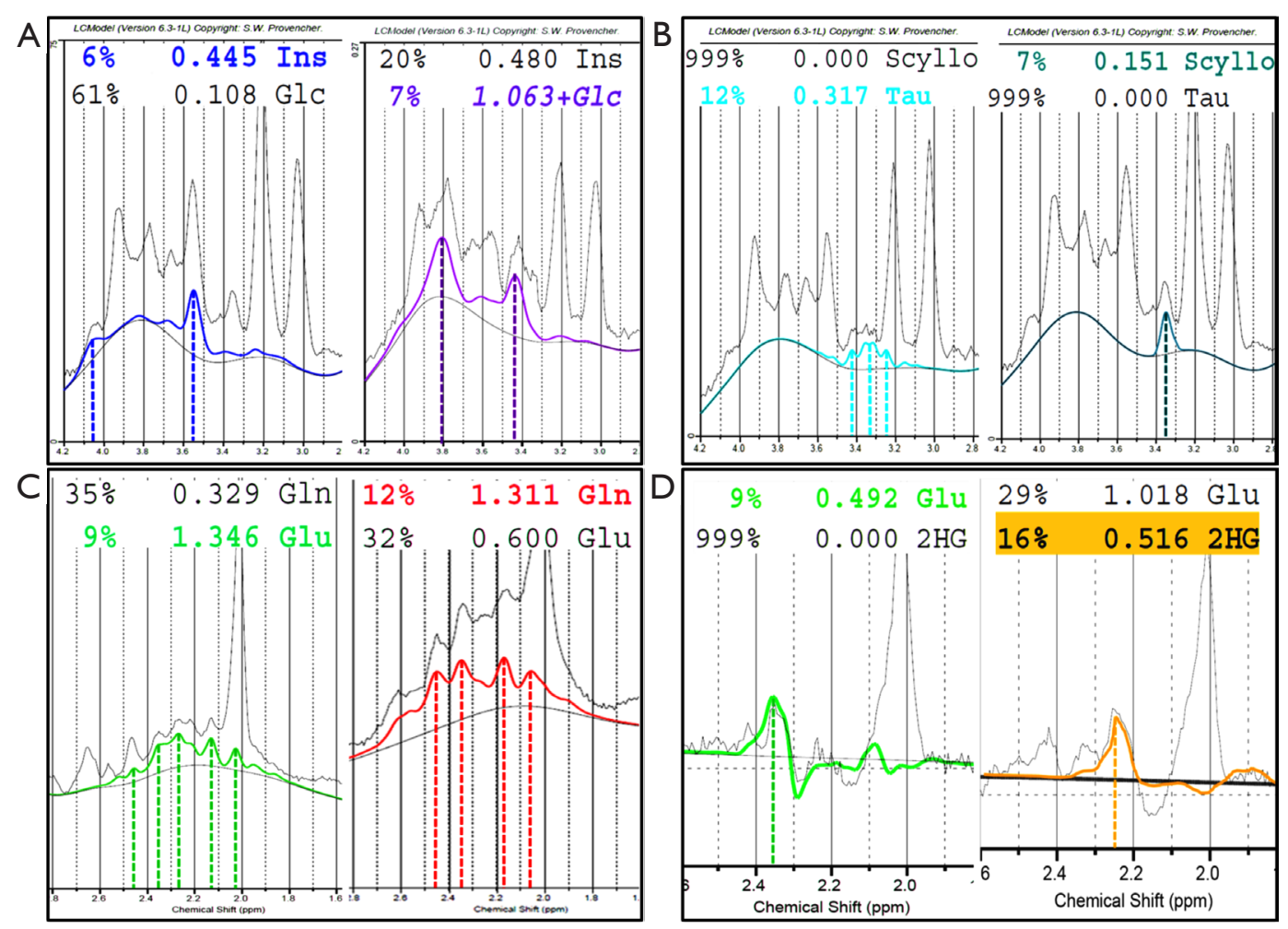

Figure 4 Various examples of the usefulness of advanced post-processing analysis methods ("LCModel" version 6.3-1L, Stephen Provencher Inc., Oakville, ON, Canada; SVS): the experimental data are fit as a linear combination of spectra of pure compounds recorded under the same experimental conditions as the in vivo spectrum; an estimate of metabolite concentrations is provided relative to the brain water signal and to $\mathrm{Cr}_{1}$ signal; the contribution of each metabolite to the spectrum is indicated by the coloured lines. Metabolites names with an estimated uncertainty of less than 20\% (most commonly used statistical cut-off for a reliable peak assignation) are labeled in colour. In cases (A,B,C) examples of short TE PRESS spectra recorded at 1.5T are shown: in (A) myo-Inositol (Ins, left) from a normal subject, and Glucose (Glc, right) in a patient with diabetic ketoacidosis; in (B) taurine mutiplet (Tau, left), and scyllo-Inositol singlet (Scyllo, right) signals recorded respectively in normal 18-month-old and 6-year-old subjects; in (C) Glutamate (Glu) and Glutamine (Gln) complex multiplet signals respectively in a normal age-matched subject (prevalence of Glu, left) and in a 4-year-old female (prevalence of Gln, right) with hyperammoniemic encephalopathy. In (D) an optimized $97 \mathrm{~ms}$ PRESS sequence acquired at 3 Tesla shows the possible differentiation of Glu ( 2.35 ppm, left) and 2-hydroxyglutarate (2HG, $2.25 \mathrm{ppm}$, right) signals for IDH-mutated gliomas identification. Acronyms and abbreviations are shown in Appendix 1.

significant volume averaging through normal tissue.

If a more comprehensive evaluation of the chemicals distribution in normal and diseased brain is deemed necessary, CSI approach can be the right choice.

CSI, either 2D (preferred for better shimming and best outer volume suppression) or $3 \mathrm{D}$, allows spectra analyses from multiple (e.g., 64 to 256) voxels over wide volumes of interest in a relatively short time single measurement (6-8 minutes for 2D). This enables the evaluation of focal pathologies compared to adjacent ipsilateral and correspondent contralateral voxels, also allowing normalization of pathologic metabolite ratios to normal tissue. By means of CSI it is also possible to assess the distribution pattern of specific metabolites in diffuse pathological conditions (e.g., lactate in hypoxia). CSI data can be overlaid as color maps (Figure $5 A, B$ ) on anatomic conventional MRI. Moreover, for the characterization of single or multiple sharply demarcated lesions, CSI allows the retrospective selection of the ROI with a post-processing re-sampling ("grid shifting") that enables to set new CSI data for each main orientation. If CSI is not available on the MR scanner, the comparison with a control contralateral voxel in normal tissue is suggested (11). When examining systemic diseases (e.g., hepatic encephalopathy) or diffuse 


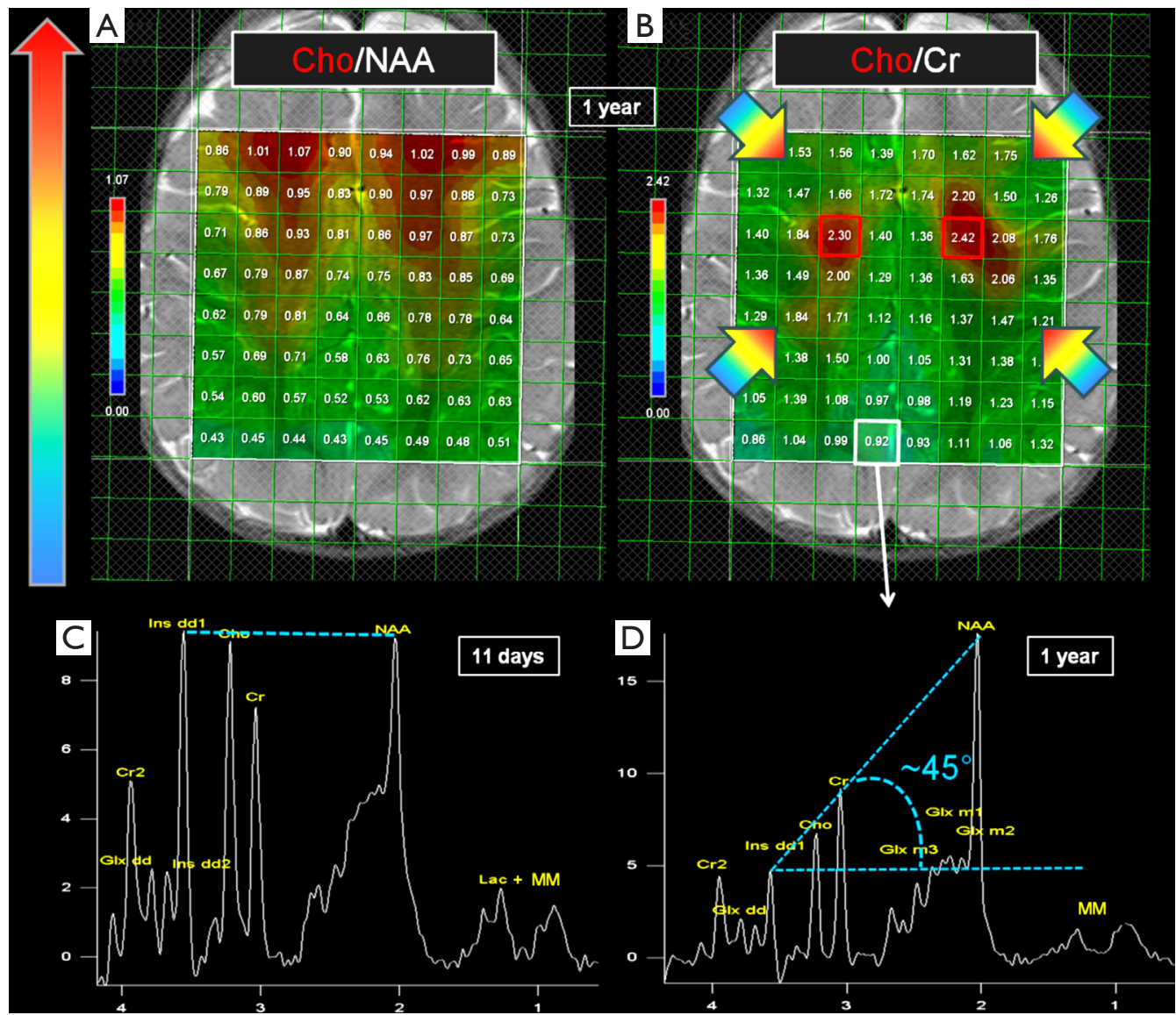

Figure 5 Top row: a 2D-CSI axial slab (1.5T, TE $135 \mathrm{~ms}$, central $8 \times 8$ color-coded grids, nominal voxel size $\left.1.5 \mathrm{~cm}^{3}\right)$ of a healthy 1-year-old female is shown; in (A) the physiological postero-anterior gradient of tCho/NAA ratio is seen; in (B), highlighted in red, the physiological maximum tCho/ Cr values (>2 at this age) in deep frontal WM matter are displayed. In (C) a single voxel MR spectrum (1.5T, TE $30 \mathrm{~ms}$ ) obtained from right posterior cingulum at 11 days postpartum in a neurologically healthy full-term newborn is shown: $\mathrm{m}$-Ins is the major peak; in the $0.9-1.4 \mathrm{ppm}$ range $\mathrm{MM}$ and Lac are often physiologically found at this age. The peaks of NAA, tCho and m-Ins "revers" by the age of 18-24 months; a spectrum (D) from the same 1-year-old subject as in (A,B) and from the same region as in (C), shows the so-called "Hunter's angle": a quick visual method to roughly define the normal "adult-like" metabolite ratios in posterior cortical areas at short TE. Acronyms and abbreviations are shown in Appendix 1.

brain pathologies, SVS can be used as well, because the changes are supposed to be similar in any analyzed region. A commonly used compromise is to acquire a short TE single voxel including the more representative part of the lesion and a multivoxel intermediate TE 2D-CSI grid encompassing the lesion and contralateral normal brain.

\section{Quantification methods}

The measurement of metabolites concentration (i.e., quantification) is essential for reproducibility, interpretation and sharing of the results in both research and clinical practice (16). The most used and simple method is the evaluation of peaks ratios, by which a metabolite signal intensity is expressed as a fraction of another: usually, $\mathrm{Cr}_{1}$ is chosen as internal reference, considering its relative constancy in many brain pathologies. However, this assumption is not true for some metabolic disorders (e.g., mitochondrial diseases) and for many tumors (e.g., medulloblastoma, meningioma, lymphoma) (Table 1). Hence, although in many cases metabolites peaks ratios provide enough information in a timely manner, if an advanced post-processing tool is available, absolute quantification has to be preferred. Different units are used to express in vivo brain metabolite concentrations (e.g., moles per unit volume, wet weight, or dry weight). 
Table 1 Examples of intracranial tumors with corresponding main characteristic $\mathrm{H}^{1} \mathrm{MRS}$ features

\begin{tabular}{|c|c|}
\hline Tumor & Main $\mathrm{H}^{1} \mathrm{MRS}$ features \\
\hline Medulloblastoma & $\begin{array}{l}\text { high tCho \& Glyc }{ }^{\dagger} \text {; low } \mathrm{Cr} \& \mathrm{NAA}^{\dagger} \text {; high Tau } \\
\text { \& } \mathrm{GAA}^{\ddagger}\end{array}$ \\
\hline \multicolumn{2}{|c|}{ Pilocytic astrocytomavery low $\mathrm{Cr}^{\dagger}$; high $\mathrm{Lac}^{\dagger}$} \\
\hline Ependymoma & very low $N A A^{\dagger}$; very high $m-$ Ins $^{\ddagger}$ \\
\hline IDH-mutant gliomas & $\begin{array}{l}\text { high } \mathrm{tCho}^{\dagger} \text {; low NAA }{ }^{\dagger} \text {; high } \mathrm{Lac}^{\dagger} ; 2 \mathrm{HG} \\
\text { presence }\end{array}$ \\
\hline DNET & high Lac ${ }^{\dagger}$ \\
\hline $\begin{array}{l}\text { Choroid plexus } \\
\text { papilloma }\end{array}$ & very low $\mathrm{Cr} \& N A A^{\dagger}$; very high $\mathrm{m}$-Ins ${ }^{\ddagger}$ \\
\hline Lymphoma & $\begin{array}{l}\text { high } \mathrm{tCho}^{\dagger} \text {; very low } \mathrm{Cr} \text { and } \mathrm{NAA}^{\dagger} \text {; high Lip } \\
\text { and/or } \mathrm{Lac}^{\dagger}\end{array}$ \\
\hline Meningioma & $\begin{array}{l}\text { very low } \mathrm{Cr}^{\dagger} \text {; NAA absence }{ }^{\ddagger} \text {; high Ala \& } 3.8 \\
\text { ppm peak }(\alpha-\mathrm{CH} \text { AAs) })^{\ddagger}\end{array}$ \\
\hline
\end{tabular}

${ }^{\dagger}$, aspecific; ${ }^{\ddagger}$, specific; ${ }^{\S}$, pathognomonic finding.

The most employed strategy for absolute quantification is to acquire the water signal of the brain in the selected voxel and to estimate the tissue water content, used as an internal concentration reference. Unfortunately, the exact water content ( $\sim 5 \mathrm{~mol} / \mathrm{L}$ for normal gray matter and $\sim 40 \mathrm{~mol} / \mathrm{L}$ for normal white matter) is often unknown, especially in neonatal brain and in most brain pathologies. Other quantification methods (e.g., using an external reference) require additional MR hardware and software and have also some issues (e.g., susceptibility effects) (17). A more complete discussion of this topic provided elsewhere $(17-19)$ is beyond the aim of this article.

\section{Voxel placement}

It is recommended to study brain regions where $\mathrm{H}^{1} \mathrm{MRS}$ is usually not affected by artifacts and where normal agematched data are available for comparison: neuroradiologists have to be aware of the age-dependent changes present mostly in the first two years of life also in normal subjects (Figure 5C,D) (20). After three years of life there are no significant differences in metabolites ratios. In our opinion, to avoid gross misinterpretations, an institutional $\mathrm{H}^{1} \mathrm{MRS}$ database (with spectra obtained on the same MR scanner at both short and intermediate TEs) should include a set of 2D-CSI data acquired at basal ganglia and supraventricular frontoparietal levels, and performed at least on two normal controls every 2-3 weeks of age from 0 to 3 months of life, every 3 months from 3 months to 2 years of life, and at least on one control per year from 2 to 12 years of life.

The spectra show variation in metabolites concentrations also according to the brain region studied (e.g., cerebellum, basal ganglia, white matter, or gray matter) $(21,22)$. For instance, NAA and $\mathrm{Cr}$ have higher concentration in the gray matter, while Choline in the white matter; NAA concentration is lower in cerebellum, total Choline (tCho) is higher in frontal white matter (Figure $5 A, B$ ), pons, and in terminal zones of myelination (23).

A typical MR spectrum from normal parietal gray matter of a 1-year-old infant with the so-called "Hunter's angle" is shown in Figure 5D.

\section{$H^{1}$ MRS artifacts}

To avoid wrong spectra interpretation, neuroradiologists should be familiar with the most common $\mathrm{H}^{1}$-MRS artifacts, such as improper water suppression, chemical shift artifact/misregistration, "voxel bleeding" (up to 10\% of signal can appear in an adjacent voxel in CSI), and voxel lipid contamination (6) (Figure 3). Voxel placement and regional variation in different brain areas influence the relative metabolites concentrations (Figure $5 A, B$ ): partial volume effects with cisternal and ventricular cerebrospinal fluid (CSF) should be minimized, unless a CSF analysis is expressly required (e.g., for Lac identification in mitochondrial diseases, see below). Voxels placement next to paranasal sinuses and bony calvarium usually impairs water suppression and causes severe susceptibility artifacts that affect shimming procedures (Figure $3 E, F$ ). "Shimming" is an iterative adjustment process used to improve magnetic field homogeneity (24). It is advised to perform a manual (second order) shimming to reach high quality results by narrowing the spectral linewidth. In order to better separate overlapping peaks at clinically available field strengths (1.5 and $3 \mathrm{~T})$, the full width at half maximum (FWHM) of a peak, that determines the linewidth, has to be set as narrow as possible $(<25 \mathrm{~Hz}$ at $3 \mathrm{~T}$ and $<15 \mathrm{~Hz}$ at $1.5 \mathrm{~T}$ ). With sufficient experience, adequate shimming can be recognized by observing the spectra (25): neuroradiologists have to evaluate peak shape (narrow peaks, not fused or duplicated) (Figure 3C), the presence of an acceptable SNR, and adequate water suppression (water peak at $4.7 \mathrm{ppm}$ should be recognizable, but not predominant) (Figure $3 B, C)$. CSI data in the 
outer voxels are often corrupted by poor magnetic field homogeneity. Spectral baseline interferences and spurious signals (Figure 3D) can originate from the tails of the huge water resonance and from water "sideband" distortions, due to subject movement, mechanical vibration and instability of radio frequency and gradient systems (26). Clinical indications should guide voxel placement and both conventional and $\mathrm{H}^{1} \mathrm{MRS}$ data should be reviewed before the exam is completed.

Chemical shift increases with magnetic field strength, allowing a better visualization of most (not all) metabolites, although the advantages of a $3 \mathrm{~T}$ acquisition can be reduced by the drawbacks of enhanced susceptibility artifacts, nonuniform radiofrequency fields, and higher radiofrequency energy tissue deposition occurring at higher fields $(27,28)$. Nevertheless, with appropriate SAR limits adjustments, $\mathrm{H}^{1} \mathrm{MRS}$ can be acquired safely at $3 \mathrm{~T}$ also in children.

Of note, contrast media administration doesn't affect the quality of the spectra (29).

\section{Brain H'MRS metabolites}

$\mathrm{H}^{1} \mathrm{MRS}$ can measure a variety of metabolites (up to $\sim 40$ at 3T using advanced post-processing softwares): the most important identified with 1.5 and $3 \mathrm{~T}$ MR scanners are listed below.

\section{$N$-acetyl-aspartate (NAA)}

The precise role of NAA is not yet well understood (30), but this molecule is widely used as surrogate marker of the degree of neuronal/axonal integrity in brain diseases. NAA is synthesized from acetyl co-enzyme $\mathrm{A}$ and aspartate in neuronal mitochondria, diffuses along axons and is broken down by cytosolic deacetylation in oligodendrocytes $(31,32)$. In most cases, NAA reduction is a non-specific finding (Figure 6), but its quantification can guide the diagnosis. NAA has three resonance peaks: the first $\left(\mathrm{NAA}_{1}\right.$, the most prominent peak in the spectrum) is a singlet at $2.02 \mathrm{ppm}$ and is due to three magnetically equivalent protons of its acetyl group (Figure 1). It is important to recognize the two other peaks at $2.67\left(\mathrm{NAA}_{2}\right)$ and $2.5 \mathrm{ppm}\left(\mathrm{NAA}_{3}\right)$, which may be mistaken for Glu/Gln/GABA peaks or misinterpreted as pathologic additional peaks. NAA is low in a healthy developing newborn and increases rapidly with brain maturation (Figure 5C,D), becoming the dominant peak by 6 months of age (3) and reaching its zenith at approximately
10-15 years (33). NAA concentrations also vary in healthy subjects above the age of 3, ranging from $\sim 8$ to $\sim 10 \mathrm{mmol} /$ $\mathrm{kg}_{\mathrm{ww}}$. This can affect NAA quantification in case of mild brain injuries, so that NAA measurements relative to the mean concentration of age-matched control subjects (preferably acquired on the same MR scanner) are highly recommended.

\section{Total choline (tCho)}

The second prominent peak in the spectrum is commonly referred to as "total Choline" (tCho): despite its relatively low brain concentration (only 1-2 mmol/ $\mathrm{kg}_{\mathrm{ww}}$ ), it is a huge singlet, result of the signal originating from several magnetically equivalent protons that co-resonate at $\sim 3.2 \mathrm{ppm}$, and of its long T2 decay time (Figure $1 \mathrm{~B})$. Phosphorylcholine $(\sim 0,6 \mathrm{mM})$ and glycerophosphorylcholine (GPC, $\sim 1 \mathrm{mM}$ ) account for most of the tCho detected with $\mathrm{H}^{1} \mathrm{MRS}$ in normal brain $(7,34)$. tCho levels decrease during and after the postnatal period until the age of 3 years (3). No signal is usually observed from phosphatidylcholine (a major constituent of membranes) because of its very short T2 value. Elevated tCho signal is associated with increased membrane turnover (e.g., in tumors, ischemia, demyelination, inflammation and gliosis). GPC can also act as a cerebral osmolyte (35) that influences tCho levels according to hypo- or hyper-osmotic states (see below).

\section{Creatine (Cr)}

The third major peak in $\mathrm{H}^{1} \mathrm{MRS}$ spectra is due to creatine, a singlet at $3.03 \mathrm{ppm}\left(\mathrm{Cr}_{1}\right)$ originating from the $\mathrm{CH}_{3}$ group of the molecule. If a proper water suppression is achieved, a second peak $\left(\mathrm{Cr}_{2}\right)$ is recognized at $3.91 \mathrm{ppm}$, a singlet originating from the $\mathrm{CH}_{2}$ group (Figure 1). The maintenance of the relative peak heights $\left(\mathrm{Cr}_{2} / \mathrm{Cr}_{1}=2 / 3\right.$, i.e., the ratio of the number of protons) can thus be used as a good quality check of the suppression of water signal at 4.7 ppm (6) (Figure $3 A, B)$. Cr peaks have equal contributions from free creatine (fCr) and phosphocreatine (PCr) which are used to maintain ATP levels and are in rapid chemical exchange. Therefore, it can be considered a marker of the potentially available energy. $\mathrm{Cr}$ concentration increases rapidly before and around term $(33,36)$. Because the $\mathrm{Cr}$ concentration $(7-8 \mathrm{mM})$ has been reported to be relatively stable in the vast majority of brain pathological conditions, 


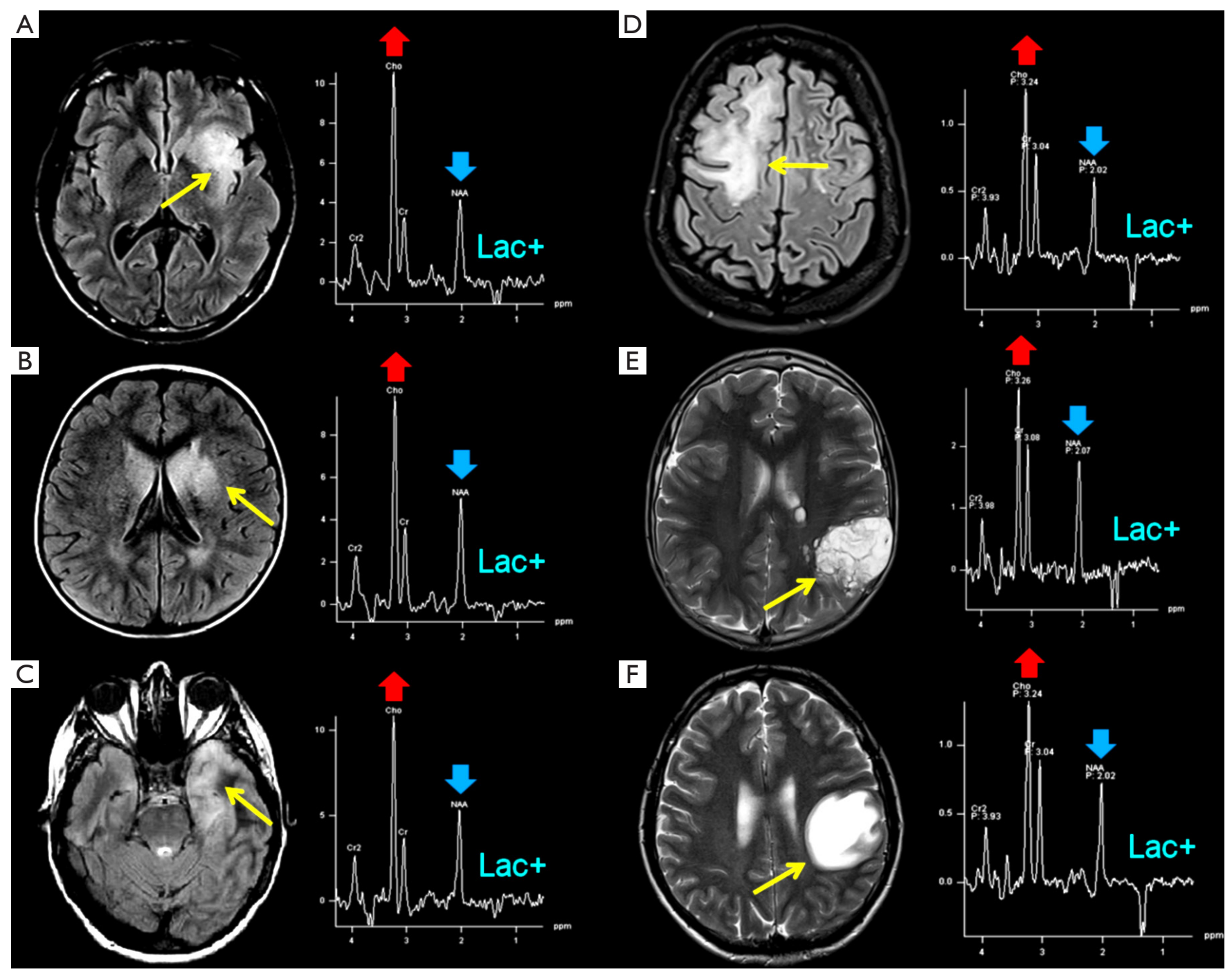

Figure 6 Similar non-specific intermediate TE spectral pattern seen at 1.5T (Lac presence, inversion of NAA/tCho ratio) in 6 different pathologies in pediatric patients (voxel placed in areas of abnormal signal on T2-WI, yellow arrows): (A) low grade WHO II astrocytoma; (B) acute disseminated encephalomyelitis (ADEM); (C) herpes encephalitis; (D) progressive multifocal leukoencephalopathy (PML); (E) dysembryoplastic neuroepithelial tumor (DNET); (F) "tumor-like" multiple sclerosis plaque. Acronyms and abbreviations are shown in Appendix 1.

$\mathrm{Cr}_{1}$ is commonly used as the reference peak.

\section{Myo-inositol (m-Ins)}

tCho, $\mathrm{Cr}$ and NAA can be easily visualized and possibly quantified in short, intermediate, and long TE $\mathrm{H}^{1} \mathrm{MRS}$. It is usually said that short $\mathrm{TE} \mathrm{H}^{1} \mathrm{MRS}$ is mandatory for m-Ins visualization, but this metabolite can be seen, also with intermediate TEs, although to a lesser degree (Figure 1). Myo-Inositol is the most abundant isomer of Inositol, a glucose-derived carbocyclic sugar alcohol.
Although m-Ins can reach high concentrations also in normal brain (from $\sim 5$ up to $\sim 8 \mathrm{mM}$ ), its signal splits between six coupled protons. At $1.5 \mathrm{~T}$ it shows a main resonance signal $\left(\mathrm{m}-\mathrm{Ins}_{1}\right)$ at 3.56-3.57 ppm (Figures 1,4A); increased spectral dispersion at higher fields produces two distinct peaks (i.e., 3.55 and $3.61 \mathrm{ppm}$ at $3 \mathrm{~T}$ ) actually reducing the signal intensity by half; a second smaller peak $\left(\mathrm{m}-\mathrm{Ins}_{2}\right)$ is often detected at 4.05-4.06 ppm and can be used as another index of excellent water suppression (Figures 1,4A) (6). Similarly, to tCho, m-Ins is described as an astroglial marker (sometimes increased in gliomas) (37) 
and as an osmolyte (reduced in hyponatremia and hepatic encephalopathy) $(35,38,39)$; it is also a component of neural receptor signaling systems, and its levels change in response to alteration of membrane metabolism or damaged membrane. It is physiologically high in neonatal brain and decreases to adult levels within the first 24 months of life (Figure 5C,D). At short TEs, m-Ins ${ }_{1}$ can be confounded with an abnormally high glycine peak at $\sim 3.55 \mathrm{ppm}$.

\section{Glutamate (Glu) and glutamine (Gln)}

Glutamate is the major excitatory neurotransmitter in the nervous system and the metabolite that has the highest concentration $(\sim 10 \mathrm{mM})$ in normal brain (40). Glutamine (concentration $\sim 5 \mathrm{mM}$ ) is a non-essential amino acid and a precursor of Glutamate with which it shares a composite resonance pattern, due to the undesired effect of J-coupling. At $1.5 \mathrm{~T}$, because of the almost complete overlap of Glu and Gln resonances, they are usually labeled as the composite peak "Glx". The first visible peak at the left side of the spectrum $(\alpha-G l u+\alpha-G l n=" \alpha-G l x ")$ shows $\mathrm{CH}$ (methine) resonances between 3.6 and $3.9 \mathrm{ppm}$, whereas the $\mathrm{CH}_{2}$ (methylene) groups $(\beta, \gamma-\mathrm{Glu}+\beta, \gamma-\mathrm{Gln}=$ " $\beta, \gamma-\mathrm{Glx}$ ") produce an even more complex series of resonances between 2.0 and $2.6 \mathrm{ppm}$. A reliable separation is possible at 3 Tesla only for $\beta, \gamma$-Glu and $\beta, \gamma$-Gln and requires a high spectral quality and the use of advanced post-processing softwares, e.g., LCModel (41) (Figure 4), jMRUI (42), TARQUIN (43), ProFit (44), OXSA (45) that can fit all metabolite resonances simultaneously and indicates those ones with acceptable reliability. The accurate quantification of these metabolites is difficult also using optimized protocols with spectral editing sequences (e.g., MEshcher-GArwood Point RESolved Spectroscopy, MEGA-PRESS) $(2,46)$. The combined role of Glu and Gln is complex: Glu-Gln cycle is integrated with glycolysis, Glu (mainly stored in neurons) is a substrate for gamma-aminobutyrate (GABA) and glutathione (GSH) synthesis and is involved in excitotoxicity-mediated pathological processes. Gln concentration is higher in astrocytes and its levels are found to increase in hypoxic states and in hyperammonemic disorders (47).

\section{Lactate (Lac)}

During physiological aerobic conditions, Lac is present in normal brain tissue at concentrations of $0.3-1 \mathrm{mM}$
( 1 $\mathrm{mM}$ in cerebrospinal fluid) (3). Lac increases when its oxidation in the Krebs cycle is impaired (e.g., in hypoxia or mitochondrial diseases) (Figures 2,7,8) and so it is an indicator of anaerobic metabolism. It shows a typical doublet at $1.33 \mathrm{ppm}$ with $\sim 7 \mathrm{~Hz}$ splitting. Confirmation of the assignment of this resonance peak can be done by varying the echo times: at intermediate TEs Lac resonance shows a phase of $180^{\circ}$ leading to a negative in-phase doublet (inverted below the baseline), while at short and long TEs the doublet is upright (Figure 2). In healthy preterm infants brain Lac concentrations can reach 0.9-2.4 $\mathrm{mM}$ ) (3), likely reflecting an immature stage of enzyme development (48). Unfortunately, Lac identification is often a nonspecific finding (Figure 6): it can accumulate in tumors, inflammatory processes, demyelination, necrotic tissues, and cysts. It can be more useful when found in normalappearing parenchyma (Figure 8).

\section{Lipids and macromolecules (Lip + MM)}

In the $\mathrm{H}^{1} \mathrm{MRS}$ spectrum, the protons of the $\mathrm{CH}_{3}$ (methyl) groups of lipid molecules generate a minor peak at $\sim 0.9$ ppm, whereas protons of the $\mathrm{CH}_{2}$ (methylene) groups is responsible for the main peak at $\sim 1.3 \mathrm{ppm}$. Other lesserknown Lip peaks exist at $\sim 2.0-2.3$ and $\sim 2.8$ ppm (49). All the Lip resonance peaks are broad and overlap with other macromolecules (MM: main peak at $\sim 0.9$ ppm; other peaks at $~ 1.4-1.5,1.7,2.1,3,3.3$, and $3.9 \mathrm{ppm})(49,50)$. At short TEs, particularly in myelinating brain of the first years of life, Lip + MM are normally visible in the above-mentioned ppm ranges and can sometimes lead to fluctuating baselines and other peaks overestimation (e.g., $\mathrm{Cr}_{2}, \mathrm{Lac}, \mathrm{Glx}$, NAA) (49) (Figure 2). At intermediate and long TEs, in normal brain tissue, Lip and MM show very little or no signal. Lipid signal increases when breakdown of cell membrane and release of fatty acids occur and they are therefore significant markers for necrosis and severe brain injury. In active demyelinating lesions (49) and in lower grade glial tumors (51) a major MM expression can be found. At short TEs, a proper separation of Lip and MM can be achieved only in post-processing with accurate basis sets (LCModel), but they can be grossly differentiated by the relative proportion of 0.9 and $1.3 \mathrm{ppm}$ peaks (49) (Figure 2C,D).

\section{Taurine (Tau)}

Taurine is an amino acid with functions including 

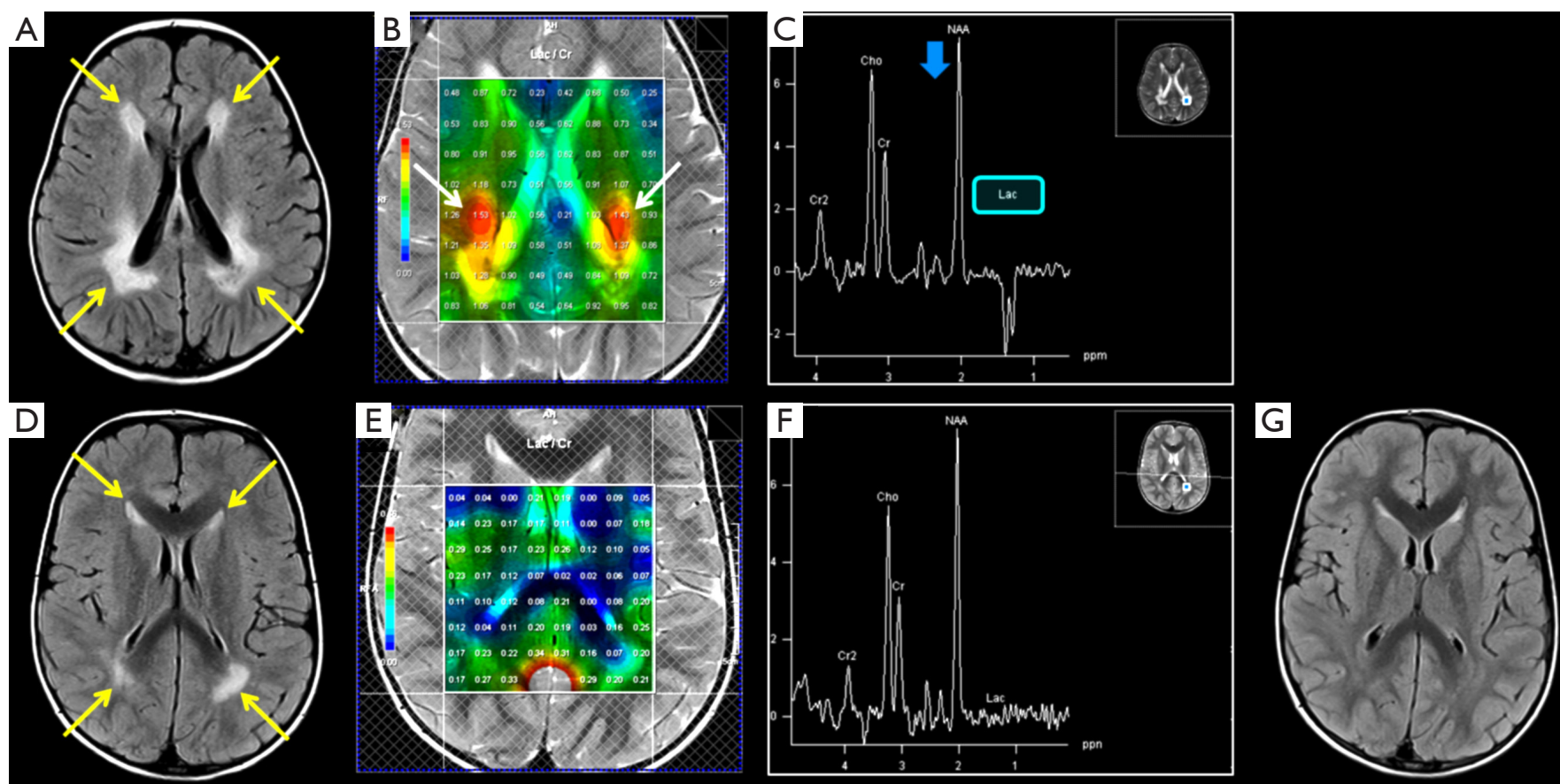

Figure 7 Comparison of two females with similar conventional MRI (yellow arrows in A and D indicate hyperintense signal on axial FLAIR sections) and striking different spectroscopic imaging findings at 1.5T (pseudo-color Lac/Cr metabolite maps, 2D-CSI in B and E; intermediate $\mathrm{TE}$ individual spectra from left paratrigonal voxels in $\mathrm{C}$ and $\mathrm{F}$ ). Top row: a 22-month-old girl with psychomotor retardation and metabolic acidosis of undetermined etiology. Lac elevation and NAA reduction through the entire section are seen, mainly in peritrigonal WM (white arrows in B, spectrum in C). A mitochondrial complex III deficiency (LYRM7 gene mutation) was confirmed. Bottom row: a 26-month-old girl with macrocrania and no other significant symptoms. Lac and NAA levels are in normal range. A 2-year follow-up confirmed FLAIR signal normalization (G) consistent with normal WM maturation. Acronyms and abbreviations are shown in Appendix 1.

osmoregulation and modulation of neurotransmitters' action. It is particularly abundant in developing cerebellum and immature neocortex at the time of birth, and decreases with age to a concentration of $\sim 1.5 \mathrm{mM}$ (52) that makes its detection difficult, also for the spectral overlap with tCho, scyllo-Inositol and Glucose. Theoretically, the two triplets peaks resonating at 3.25 and $3.42 \mathrm{ppm}$ (Figure $4 B$ ) should be better visible at 3 Tesla; practically, in vivo visualization at 1.5 Tesla exploits peak "fusion" at $\sim 3.35 \mathrm{ppm}$ (6) (Figures 4B,9). Pathologically elevated Tau is detectable in most medulloblastoma molecular subtypes (53-55) (Table 1).

\section{Scyllo-inositol (s-Ins)}

It is the other stereoisomer of Inositol visible in $\mathrm{H}^{1} \mathrm{MRS}$ at both short and intermediate TEs, despite its low concentration $(<1 \mathrm{mM})$, thanks to its singlet peak at $3.36 \mathrm{ppm}$, arising from the six magnetically equivalent protons. It should not be confused with Tau, which has a more complex pattern (see above) or with other alleged abnormal pathological peaks (Figure 1A,B, Figure 4B, Figure 9D,E,F,G).

\section{Glycine (Glyc)}

It is a simple amino acid that acts as an inhibitory neurotransmitter and antioxidant (7). Glyc has a concentration of $\sim 1 \mathrm{mM}$ and a singlet peak at $3.55 \mathrm{ppm}$ which is better identified at $1.5 \mathrm{~T}$ using intermediate and long TEs sequences which avoid the overlapping with $\mathrm{m}$-Ins multiplet. It is found in nonketotic hyperglycinemia (NKH) (56) (Figure 10) and it is also positively correlated with tumoral WHO grade (seen in medulloblastoma and glioblastoma multiforme, GBM) (Figure 9B,C) (57-59).

\section{2-bydroxyglutarate (2HG)}

$2 \mathrm{HG}$ is not visible in healthy tissue; it is detectable only 


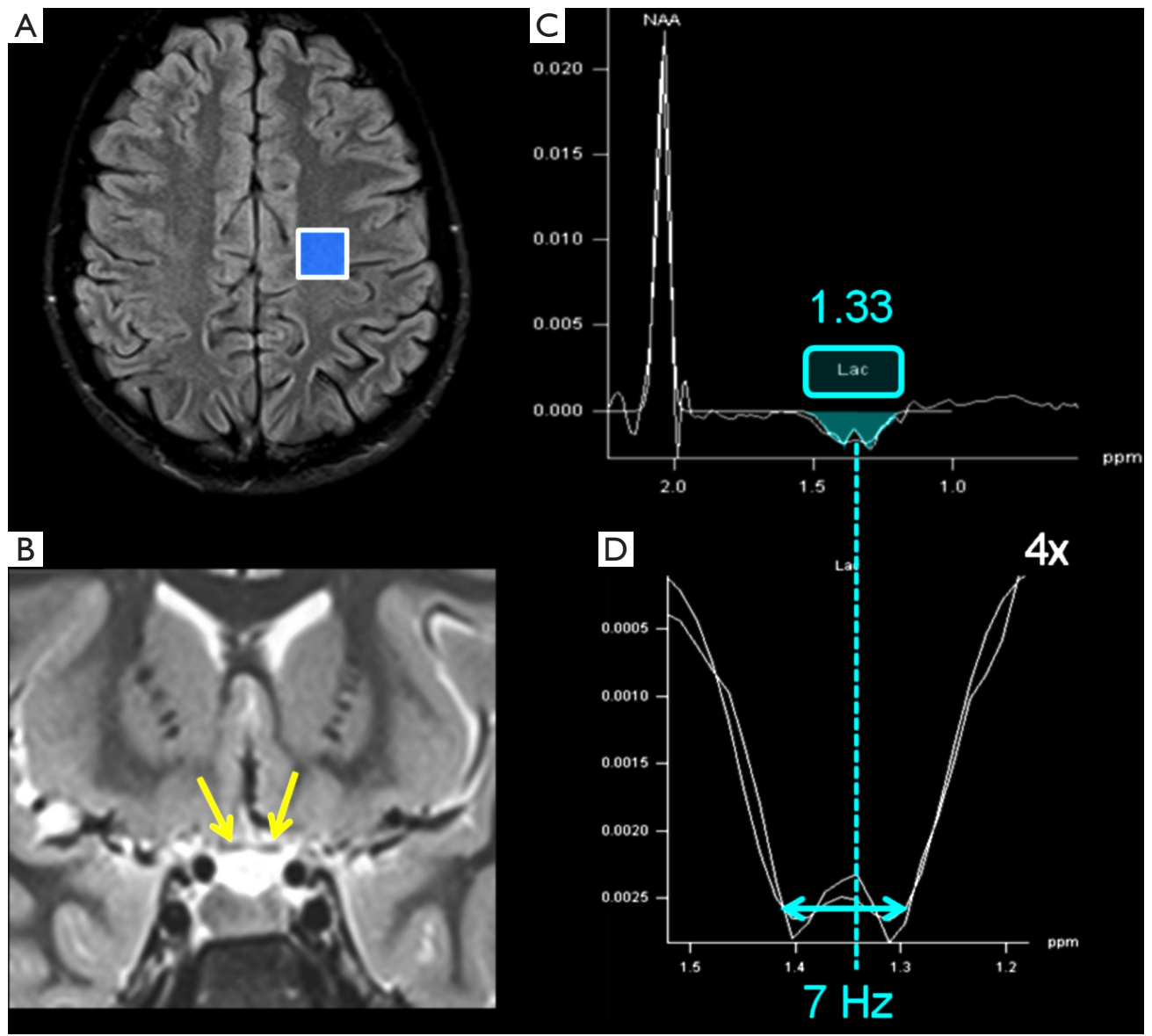

Figure 8 A girl experiencing progressive visual loss with nystagmus and no other symptoms except for migraine from the age of 15 . Conventional MRI showed progressive optic atrophy, in absence of brain pathology (A, axial FLAIR image; B, yellow arrows in coronal STIR T2-WI). Among the four $\mathrm{H}^{1} \mathrm{MRS}$ studies acquired at 1.5T between 16 and 23 years of age, only the spectra obtained in the third follow-up (a voxel from left frontal watershed zone is shown in C) allowed to identify the characteristic Lac doublet, inverted at intermediate TE (135 ms) and centered at 1.33 ppm (4x magnification in D) with a J-coupling constant of nearly $7 \mathrm{~Hz}(\sim 0.1 \mathrm{ppm}$ at $1.5 \mathrm{~T})$. Clinical and instrumental investigations were eventually consistent with the diagnosis of Leber's hereditary optic neuropathy. Acronyms and abbreviations are shown in Appendix 1.

when it accumulates due to isocitrate dehydrogenase 1 and 2 (IDH1/2) enzymes mutations. Among its 5 proton resonances, only the peaks at 4.02 and $2.25 \mathrm{ppm}$ are realistically measurable in "IDH1/2-mutant" gliomas with specific MRS protocols at 3 Tesla $(13,14,60)$ (Figure $4 D)$. It could be also found in the rare neurometabolic disorder 1-2hydroxyglutaric aciduria $(61,62)$.

\section{Alanine (Ala)}

$\mathrm{Ala}$ is an amino acid that can be seen only at pathologically high concentrations and that forms a characteristic doublet (inverted at intermediate TE) at $1.48 \mathrm{ppm}$ with $7 \mathrm{~Hz}$ splitting, analogous to that of Lac. It is detected mainly in some meningioma subtypes $(55,63)$ (Table 1) and in several pyogenic abscesses (Figure 11) or occasionally in medulloblastomas (55) (Figure 9E) and mitochondrial diseases $(6,64)$.

\section{Branched-chain amino acids (BCAAs: valine, leucine, isoleucine)}

They are the "fingerprint" of maple syrup urine disease (MSUD) (65-67) and of many brain abscesses and are characterized by a broad peak, inverted at intermediate TE, in the 0.95-1.05 ppm range (Figure 11B,C,E) (68-70). 


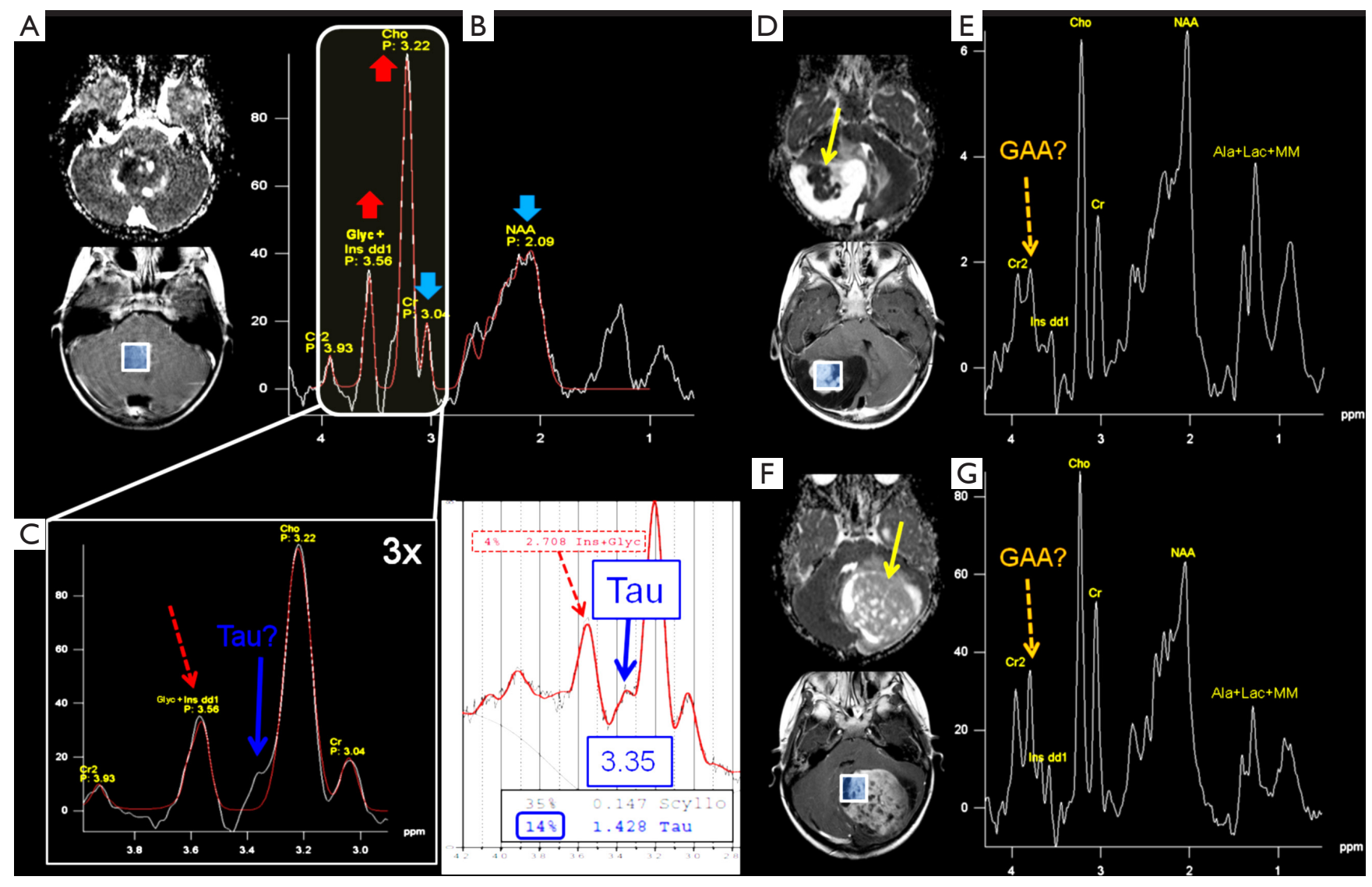

Figure 9 Differential diagnosis between classic midline ("Group 3") MB (A,B,C), atypical off-midline ("SHH-activated desmoplastic/ nodular") MB (D,E) and pilocytic astrocytoma (F,G), respectively in a 10-year-old boy, a 2-year-old boy and a 4-year-old girl; in (A,D,F) DWI ADC maps and post-gadolinium T1-WI are shown. (A) The short TE spectrum at 1.5T, centered in the solid component of the "classic" MB, shows total NAA absence, marked Cr reduction, tCho elevation, and a prominent m-Ins + glycine (Glyc) peak at $\sim 3.56$ ppm (red dotted arrows in magnified 3x spectra in C). Despite the non-optimal spectral resolution, Tau signal (dark blue thin arrows in magnified $3 \mathrm{x}$ spectra in C) is detectable at around $3.35 \mathrm{ppm}$ as a small hump partially fused with the left shoulder of the prominent tCho peak; in this case an advanced post-processing confirmation (LCModel estimation in C, right plot) was needed, and relevant s-Ins contribution was ruled out checking its singlet absence in the intermediate TE spectrum. In (D,E,F,G) are shown two tumors with relevant cystic components sharing similar conventional imaging and short TE spectra findings at 1.5T: Tau absence (s-Ins singlet detected by LCModel at $~ 3.36$ ppm), possible GAA presence at $3.78 \mathrm{ppm}$ (orange dotted arrows in E and G) and comparable spectral patterns with Ala + Lac $+\mathrm{MM}$ peaks were seen. In this cases, $\mathrm{H}^{1} \mathrm{MRS}$ was potentially misleading, while $\mathrm{ADC}$ values (yellow arrows in $\mathrm{D}$ and $\mathrm{F}$ ) provided a better clue to the diagnosis of atypical MB (D,E) and pilocytic astrocytoma (F,G), respectively. Acronyms and abbreviations are shown in Appendix 1.

\section{Other metabolites}

The primary human brain inhibitory neurotransmitter GABA, Glutathione (GSH), glucose (Glc, Figure 4A), and some $\alpha-\mathrm{CH}$ amino acids (i.e., lysine, arginine, and serine, Table 1) (63) are identifiable only in particular conditions and with Model-based spectral fitting methods like LCModel (41).

\section{Exogenous compounds}

Some xenobiotics which cross the blood-brain barrier can generate additional (often "unwanted") peaks: propylene glycol (PG) (a solvent for drugs, like phenobarbital and phenytoin), showing at intermediate TEs an inverted methyl doublet with $\sim 7 \mathrm{~Hz}$ splitting centered at 1.131.15 ppm (confusingly similar to Lac peak), and also "in- 


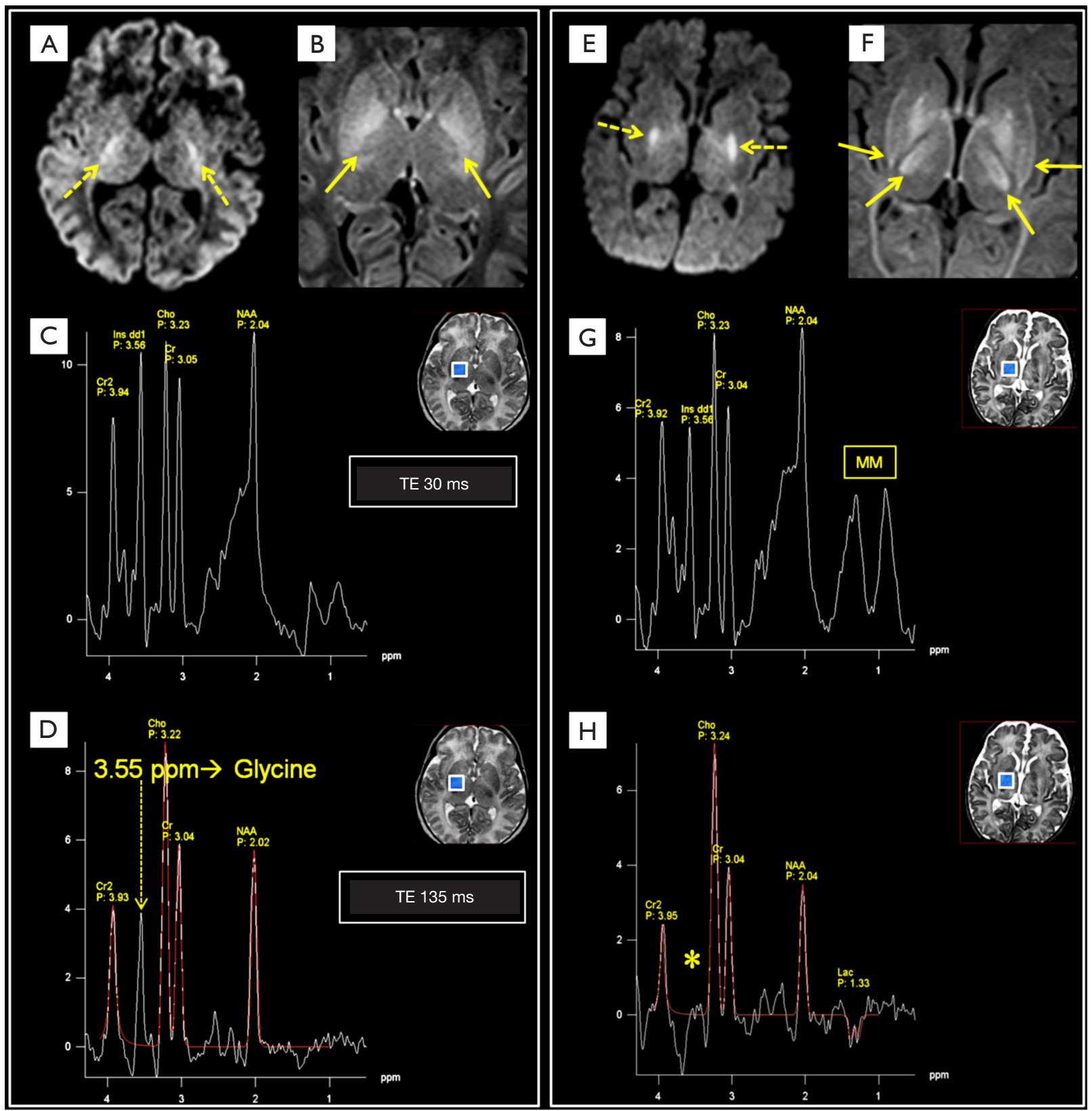

Figure 10 Comparison between 2 newborns with similar symptoms, DWI, and short TE spectra. Left panel: a 3-day-old male full-term newborn with severe hypotonia and respiratory failure. Conventional MRI discloses restricted diffusion (dotted arrows on axial $b=1,000$ DWI through basal ganglia in A) and absent physiological myelination signal on axial T1-WI (arrows in B) in the posterior limbs of the internal capsule (PLIC). Short TE spectrum (C) demonstrates a peak at 3.56 ppm, which usually represents m-Ins, but intermediate TE (D) spectrum reveals a persistence of a "singlet" peak at $3.55 \mathrm{ppm}$, consistent with glycine (in all voxels, not shown). Nonketotic hyperglycinemia (NKH) was genetically confirmed. Right panel: a 10-day-old male full-term neonate born of consanguineous parents suffering from severe cardiorespiratory failure. Axial DWI (E) and T1-WI (F) demonstrate, respectively, restricted diffusion in globi pallidi (dotted arrows in E) and reduced signal in PLIC; also bilateral lesions in lateral putamina and thalami (arrows in F) are seen. The spectra from a similar VOI as in left panel case, encompassing right thalamus and PLIC, reveal at intermediate TE a nearly complete m-Ins multiplet disappearance (asterisk in H), a slightly decreased NAA, and an inconstant minimal Lac elevation; a marked MM increase seen at short TE (G) is the only significant difference with the spectrum in (C). These findings rule out NKH. The patient died before a definitive diagnosis could be reached (uncertain between a metabolic disease and a severe HIE). Acronyms and abbreviations are shown in Appendix 1. 


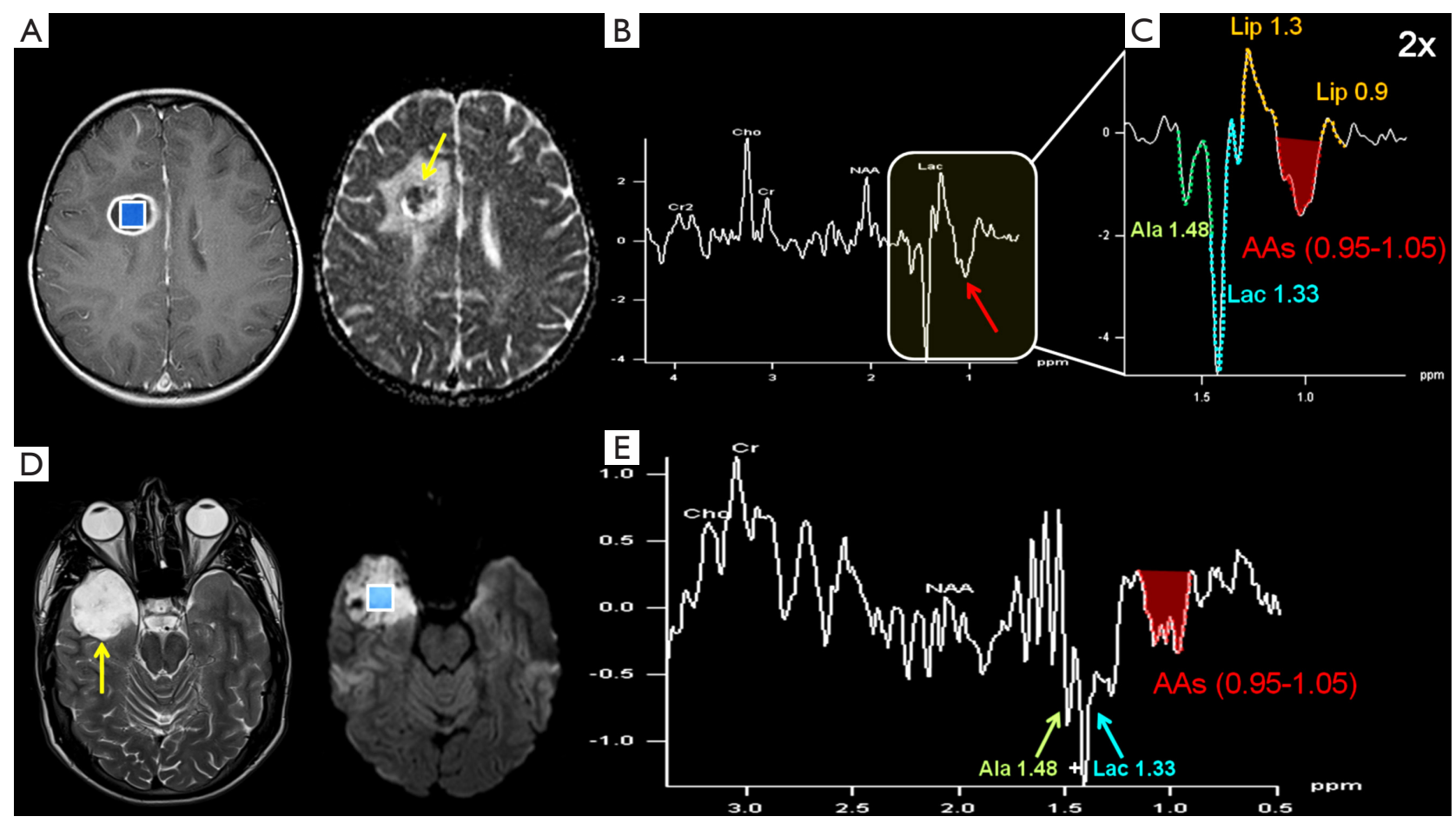

Figure 11 Top row. A 4-year-old female suffering from sudden headache, nausea and a first epileptic seizure: (A) axial post-gadolinium T1WI shows the selected $\mathrm{H}^{1}$ MRS voxel (2D-CSI; TE $135 \mathrm{~ms} ; 1.5 \mathrm{~cm}^{3}$ nominal size) chosen inside a well-defined hypointense lesion with ring enhancement in the right frontal lobe; DWI (yellow arrow in ADC map in A) shows inhomogeneous signal with both restricted and increased diffusion within the lesion. Despite some contamination from normal brain tissue, the spectrum clearly depicts the resonances of Ala + Lac (1.48 \& $1.33 \mathrm{ppm})$, Lip (1.3 \& $0.9 \mathrm{ppm})$, and cytosolic amino acids (AAs, 0.95-1.05 ppm, red arrow in B and red area in $2 \times$ magnified spectrum in C). The resonances from Ala, Lac, and AAs are inverted at this intermediate TE value, owing to J-modulation. Ala and Lac resonances are partially fused (a prominent "sum peak" is centered at $\sim 1.4 \mathrm{ppm}$ ). A pyogenic abscess (Streptococcus viridans) was confirmed after stereotactic drainage. Bottom row: right temporo-polar epidermoid cyst (T2-hyperintense signal, restricted diffusion and SVS VOI placement fully inside the lesion are depicted in D) in a male patient which became symptomatic at the age of 20 (headache and a first epileptic seizure). The $135 \mathrm{~ms}$ TE spectrum (E) demonstrated a complex "sum peak" similar to the one in (B), within the 0.9-1.5 ppm frequency range, but without significant Lip contribution. An inflammatory reaction in the context of the epidermoid cyst, maybe responsible for the onset of symptoms, was neuropathologically proven after resection of the lesion. Acronyms and abbreviations are shown in Appendix 1.

phase" methylene protons at 3.4-3.6 ppm, coincident with peaks arising from m-Ins, Tau and Glyc (Figure 12) (71-73); mannitol (at $3.8 \mathrm{ppm}$, often used to reduce brain edema) (74); acetone (at 2.2 ppm, e.g., during ketogenic diet for epilepsy) (75); methyl-sulfonyl-methane (MSM) (at $3.15 \mathrm{ppm}$, used in dietary supplements as a source of sulfur and for joint pain treatment) (76).

In Tables 2,3 are listed some of the additional metabolites cited in this section.

\section{Clinical applications}

Subtle or dramatic variations of the $\mathrm{H}^{1}$ MRS biochemical fingerprint in brain tissue can be seen essentially in three pathologic conditions (6): (I) structural damage (e.g., neoplastic, infective or degenerative diseases, embryogenic defects); (II) abnormal physiological conditions (e.g., interruption of blood supply); (III) biochemical and genetic diseases.

\section{Structural damage}

\section{Pediatric brain tumors differential diagnosis}

In case of focal lesions such as tumors, it is mandatory to sample the correct part of the expansive process (e.g., avoiding blood or extensive calcifications, picking more 


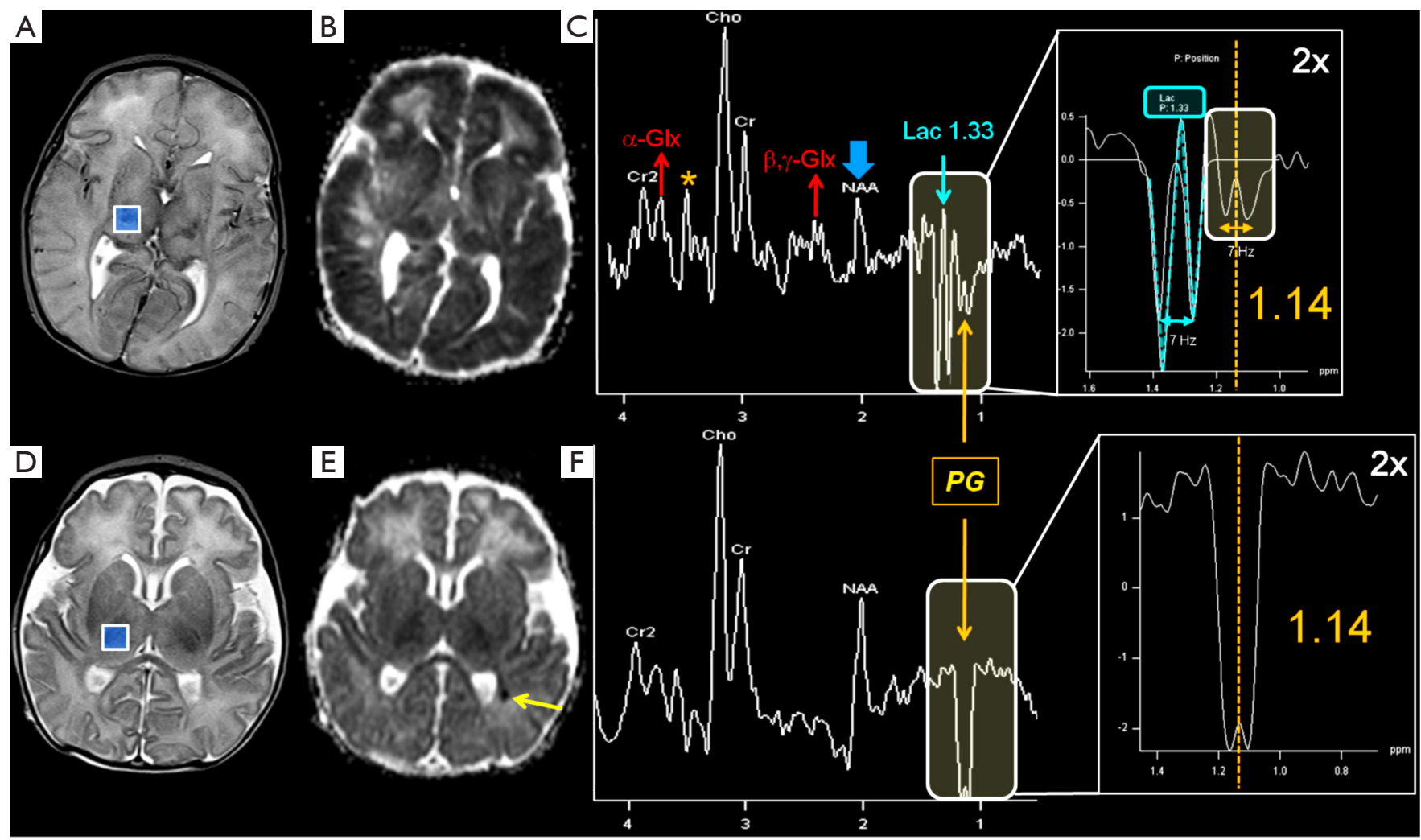

Figure 12 Top row: 5-day-old female full-term newborn, without a history of hypoxic-ischemic encephalopathy, developing on day 2 after birth repeated seizures, resistant to phenobarbital and phenytoin treatment. In conventional imaging diffuse bihemispheric edema was seen (A, axial T2-WI); DWI ADC maps (B) showed symmetric restricted diffusion in the cerebral cortex, subcortical WM, basal ganglia, and thalami, with sparing of the cerebellum (not shown). In most voxels of the intermediate TE 2D-CSI grid (right thalamo-capsular voxel depicted in A), along with a marked reduction of NAA (thick blue arrow in C) and a moderate increase of $\alpha, \beta, \gamma$-Glx peaks (thin red arrows in C), two adjacent inverted doublets (labeled respectively in light blue and orange in C) with a J-coupling constant of $\sim 7 \mathrm{~Hz}$ were seen: the peak centered at 1.14 ppm (separated from the prominent Lac peak at $1.33 \mathrm{ppm}$ ), was assigned to propylene glycol (PG), the solvent used for phenobarbital and phenytoin parenteral administration. An encephalopathy due to sulfite oxidase deficiency was hypothesized, and then confirmed. The peaks at the chemical shift range of 3.4-3.6 ppm could not be unequivocally assigned because of the possible overlap of Tau, m-Ins, and S-sulfocysteine with the other known singlet peaks of PG (orange asterisks in C). Bottom row: 8-day-old male full-term newborn with hypoglycemia, severe hypotonia, respiratory acidosis and convulsive status epilepticus treated with phenobarbital. Conventional imaging (axial T2-WI in D, DWI ADC map in E) showed only a punctate focus of coagulative necrosis in the left paratrigonal WM (yellow arrow in E). In all voxels of the intermediate TE 2D-CSI grid (right thalamo-capsular voxel depicted in D) a huge inverted doublet peak centered at 1.14, ppm (mistakable with Lac, without careful inspection) was seen and assigned to PG. The amount of NAA peak reduction was doubtful, possibly influenced by fluctuating baseline due to PG. Antiepileptic therapy was changed (phenobarbital was discontinued as a precaution), the patient significantly improved during the following weeks and, to date, no metabolic disease has been found. Acronyms and abbreviations are shown in Appendix 1.

solid cellular parts instead of or cystic/necrotic components, keeping not too close to the skull, etc.) (6).

\section{Posterior fossa tumors}

The majority of pediatric brain tumors is found in the posterior fossa. Medulloblastoma (MB), pilocytic astrocytoma (PA), diffuse midline glioma and ependymoma account for the vast majority of these primitive tumors. Diffuse midline gliomas are easily diagnosed with conventional MRI and do not have distinctive spectroscopic hallmarks. $\mathrm{H}^{1} \mathrm{MRS}$ can aid the differential diagnosis of mixed solid and cystic/necrotic tumors. Taurine peak, although not always easily recognized (Figure $9 A, B, C$ ), is observed with short TEs sequences in $M B$ solid portions 
Table 2 Metabolic diseases and corresponding pathological brain metabolites, with known main peaks positions (resonant frequencies in parts per million, ppm)

\begin{tabular}{|c|c|c|}
\hline Disease & Metabolite & Position (ppm) \\
\hline Diabetic ketoacidosis (DKA) & $\beta$-OH-Butyrate/Glucose & $1.2 / 3.43 \& 3.80$ \\
\hline Canavan disease & $\mathrm{N}$-acetylaspartate (NAA) & $2.02 \& 2.5 \& 2.67$ \\
\hline Salla disease & $\mathrm{N}$-acetyIneuraminic acid (NANA) & $2.02 \& 4$ \\
\hline L-2-hydroxyglutaric aciduria & 2-hydroxyglutarate (2HG) & 2.25 \\
\hline Pyruvate dehydrogenase deficiency (PDHD) & Pyruvate & 2.37 \\
\hline Mitochondrial complex II deficiency & Succinate & 2.40 \\
\hline HMG CoA lyase deficiency & 3-OH-isovaleric acid/3-OH 3-methyl glutaric acid & 2.42 \\
\hline Non-ketotic hyperglycinemia (NKH) & Glycine & 3.55 \\
\hline Polyols leukoencephalopathy & Arabinitol and Ribitol & $3.5-4(3.7)$ \\
\hline Galactosemia & Galactitol & 3.7 \\
\hline Phenylketonuria (PKU) & Phenylalanine & 7.3 \\
\hline
\end{tabular}

${ }^{\dagger}$, branched-chain amino acids; ${ }^{\ddagger}$, branched-chain $\alpha$-keto acids.

Table 3 List of the main known xenobiotics that cross the bloodbrain barrier, with corresponding main peaks positions (frequencies in parts per million, ppm)

\begin{tabular}{ll}
\hline Xenobiotic & Position (ppm) \\
\hline Propylene glycol (PG) & $1.13-1.15$ \\
Ethanol & 1.18 \\
Methyl-sulfonyl-methane (MSM) & 3.15 \\
Methanol & 3.35 \\
Mannitol & 3.8 \\
\hline
\end{tabular}

$(53,54,77,78)$ and, along with tumor location, DWI and enhancement pattern (79-83), may help to differentiate this entity from other tumors of the posterior fossa. Two exceptions to the rule are: (I) spectral analysis of "nonclassic" subtypes of MB (e.g., desmoplastic/nodular) $(10,84)$ (Figure 9D,E); (II) tumors with prominent cystic components affecting the sampling (Figure $9 F, G$ ). A peak at $3.78 \mathrm{ppm}$ (possibly overlapping with Glx) tentatively assigned as guanidinoacetate (GAA) (Figure 9E, G) has also been observed in MB (Table 1) and, less frequently, in PA
$(55,85)$. The most distinctive (although not pathognomonic) characteristics of pilocytic astrocytomas and ependymomas are respectively high Lac and very high $\mathrm{m}$-Ins levels $(84,86)$ (Table 1).

\section{Supratentorial tumors}

(Neuronal)-glial (e.g., dysembryoplastic neuroepithelial tumor, "DNET", astrocytomas), and embryonal tumors (e.g., atypical teratoid/rhabdoid tumors, "AT/RTs") are the main common types of supratentorial pediatric brain tumors. Some authors $(10,87)$ have observed that those tumors previously classified as supratentorial primitive neuroectodermal tumors ("s-PNET") show a spectral pattern similar to that seen in MB (very high tCho and presence of Tau) that could be useful in the differential diagnosis with extraventricular ependymoma and GBM. The few cases of $\mathrm{H}^{1} \mathrm{MRS}$ in AT/RTs seemed to show a different metabolic pattern, with more moderate Cho levels and no evidence for Tau. Non-specific high tCho/NAA and $\mathrm{Lac} / \mathrm{Cr}$ ratios are often encountered in many different tumors types (e.g., astrocytoma, oligodendroglioma, DNET) (88) (Figure 6A,E). A "sky-rocketing" m-Ins peak is a distinctive finding of choroid plexus papillomas in the 
differential diagnosis with other tumors, including choroid plexus carcinomas (10) (Table 1).

\section{Noninvasive prognostic evaluation}

$\mathrm{H}^{1} \mathrm{MRS}$ in some patients can provide useful information for the management of inoperable or only partially resectable tumors. This is the case for intra-axial tumors in eloquent cortical areas or deeply located neoplastic processes (e.g., diffuse midline gliomas). Most gliomas occur sporadically, while about $5 \%$ are associated with an underlying inherited syndrome, e.g., neurofibromatosis type 1 (NF1), LiFraumeni syndrome, and tuberous sclerosis $(89,90)$. Currently there is only one spectroscopic biomarker with high diagnostic (Table 1) and prognostic value, according to the recent WHO 2016 molecular classification of diffuse gliomas: the oncometabolite $2 \mathrm{HG}$ (see above and Figure $4 D)(13,14,60)$, detectable in "IDH-mutant" diffuse gliomas, an exceptional entity in young children, but more common in adolescents 14 years old or older. The presence of this oncometabolite leads to a better prognosis in adults (compared to "IDH-wild-type" diffuse gliomas), but likely to a worse prognosis in pediatric population, if compared to other glioma molecular subtypes (e.g., "NF1-gliomas") with an indolent course (91-95).

Increased levels of Lip, m-Ins and Glyc are positively correlated with tumor malignancy $(96,97)$. tCho signal is elevated in all brain tumors because of altered membrane turnover and in some cases (e.g., MB, oligodendroglioma) also due to high cellular density. An increase in tCho/NAA ratio has been linked to glioma high-grade transformation and prognosis (98-104), but the variable cutoffs proposed in literature make a correct tumor grading classification unreliable at first diagnosis, when it is based exclusively on the analysis of these metabolites. $\mathrm{tCho/Cr}$ and tCho/NAA ratios have been shown to be more helpful in monitoring glioma progression $(17,105)$ or in guiding stereotactic biopsy (106).

\section{Chemoradiation changes versus tumor recurrence}

Recurrent/residual tumor is often hardly distinguished from chemo/radiation necrosis using conventional imaging alone. Spectroscopy has been widely tested to assess treatment response also in pediatric brain tumors (107-113). The key point for this differential diagnosis is the $\mathrm{tCho} / \mathrm{Cr}$ (or tCho/ NAA) ratio, usually low in non-neoplastic necrosis and very elevated in residual tumor or recurrence. Cell death due to chemo/radiation treatment can result in striking elevation of Lip and reduction of all other metabolites peaks, tCho included, but in case of extensive demyelination or marked inflammatory response a misleading high $\mathrm{Cho} / \mathrm{Cr}$ ratio can be seen as well, without tumor recurrence (114-115).

\section{Neoplastic versus non-neoplastic disease}

In clinical practice, an early differential diagnosis between neoplastic and non-neoplastic diseases is often more important than the attempt to precisely differentiate or grade neoplastic lesions. There are some focal or diffuse brain pathologies that act as tumor-mimickers (e.g., infectious/inflammatory lesions, subacute ischemia, demyelination, gliosis, hamartoma) (Figure 6B, $C, D, F$ ). Conventional contrast-enhanced MRI could be misleading, and also diffusion-weighted imaging (DWI) and perfusion techniques cannot be sufficient for a correct diagnosis.

Inflammation, due to the immune response to a bacterial, fungal or parasitic infection, usually leads to formation of abscesses with different spectral patterns. In focal "ringenhancing" pyogenic brain lesions, cytosolic amino acids (AAs) accumulate due to proteolysis by enzymes released from neutrophils. The identification of the combined signal of three cytosolic AAs (isoleucine, leucine, and valine in the $0.95-1.05 \mathrm{ppm}$ range), associated or not with lactate (1.33 ppm), lipids (0.9 and $1.3 \mathrm{ppm})$, acetate (Ac, $1.92 \mathrm{ppm})$, and succinate (Suc, $2.4 \mathrm{ppm}$ ), represent a pathognomonic $\mathrm{H}^{1} \mathrm{MRS}$ finding that can corroborate the diagnosis of brain abscess, particularly in case of doubtful restricted diffusion on DWI (Figure 11A). Intermediate echo times have to be preferred to discern the complex pattern $(\mathrm{Ala}+\mathrm{Lac}+$ Lip + AAs + Lip) observed in $80 \%$ of abscesses (69) at the right end of the spectrum (Figure 11B,C). An attempt to further characterize with $\mathrm{H}^{1}$ MRS the responsible bacteria by their need and tolerance for oxygen (i.e., obligate or facultative aerobic or anaerobic) can also be made. Most obligate anaerobes and some facultative anaerobes show the presence of AAs, Lac + Lip, and Ac (with or without Suc). In most obligate aerobes or facultative anaerobes only AAs and Lac, with or without Lip, are seen $(68,69)$. Treatment with antibiotics usually causes the disappearance of all pathological peaks except that of Lac. In fungal and tuberculous abscesses lipid levels increase more than AAs levels (70).

(Epi)dermoid cysts are usually easily differentiated from malignant tumors on the basis of characteristic computed tomography attenuation values and DWI properties. The relatively rare "abscess-like" spectroscopic finding $(116,117)$ of an association of Ala and cytosolic AAs signals is likely linked with the accumulation of polymorphonuclear 
cells in (epi)dermoids due to aseptic meningitis or local inflammation (Figure 11D,E).

Regarding demyelinating processes (e.g., acute disseminated encephalomyelitis, progressive multifocal leukoencephalopathy, "tumefactive" multiple sclerosis plaque) $(118,119)$ (Figure 6B,D,F), in our experience, the differentiation from glial tumors based on MR spectroscopy alone is virtually impossible.

As far as diffuse pathologies are concerned, a study of Panigrahy et al. (120) has shown that m-Ins reduction in acute viral encephalitis can help in the difficult differential diagnosis with diffuse gliomas (121).

\section{Abnormal physiological conditions}

\section{Neonatal hypoxic-ischemic encephalopathy (HIE)}

In the newborn affected by HIE, the signal ratios of Lac/ NAA $(26,122)$ or of Lac/Cho (123) have been used as predictors of neurodevelopmental outcome, with variable cut-offs. Although Lac can be detectable in healthy neonates (mainly in preterm, but also in full-term babies) (3), its significantly high ratio to NAA or Cho indicates an adverse outcome. According to the different pathological phases of cerebral injury after HIE, Lac concentrations show a biphasic pattern: in the acute phase $(<1 \mathrm{~h})$ and during secondary energy failure phase (6-24 h to days) Lac increases (Figure 2A), while it decreases in the latent phase ( 1 to 6-24 h), after reperfusion. Usually Lac reaches a maximum at 5-6 days after injury (124) and progressively reduces after 1 week. On the other hand, NAA reduction as prognostic marker is more reliable 1-2 weeks after injury (122). In newborns with hypoxic-ischemic encephalopathy, acute injury within the first $24 \mathrm{~h}$ can be better detected by $\mathrm{H}^{1}$ MRS (elevated Lac) when both conventional imaging and DWI are doubtful or negative (125-131). Increased Lip + MM (Figures 2,10G,H) and elevated Glx (usually reversible) are typically detected after $24 \mathrm{~h}$, and decreased $\mathrm{Cr}$ signals can also be found. Lac/NAA peak ratio assessment with intermediate TEs in deep grey matter can be a useful prognostic index for neonatal HIE (132-137), while DWI can be limited by pseudonormalization of diffusion coefficient (ADC) in these patients (124).

\section{Head trauma}

There are several studies showing $\mathrm{H}^{1} \mathrm{MRS}$ capability to identify metabolite abnormalities following head accidental and non-accidental trauma (NAT). Unfortunately, they are mainly small samples studies with conflicting results (138).
Similarly, to what happens in hypoxia, Lac and Lip presence and NAA reduction are predictors for poor neurological outcome (139-142). A significant association between particularly prominent Lip peaks and poor outcome has been described in NAT (139). On the other hand, low sensitivity of $\mathrm{H}^{1} \mathrm{MRS}$ is reported for less severe brain injuries, mainly for subtle reductions in NAA concentration (143). The processes behind tCho increase in trauma are various (10) and often overlapping (damage to cell membranes in acute phase, necrotic tissue free choline accumulation and enhanced cell membrane synthesis in subacute phase, gliosis in chronic phase) $(144,145)$, making outcome prognostication particularly difficult.

\section{Biochemical and genetic diseases}

\section{Main metabolic diseases and white matter disorders}

For many pediatric patients who undergo a brain MRI scan, an additional $\mathrm{H}^{1}$ MRS study is requested by clinicians to assess inborn or acquired disorders affecting biochemical pathways. In most metabolic disorders "quantitative" $\mathrm{H}^{1} \mathrm{MRS}$ changes (i.e., NAA decrease, tCho elevation, Lac peak) are not disease-specific. However, in a few rare diseases, $\mathrm{H}^{1} \mathrm{MRS}$ allows the identification of pathognomonic "qualitative" changes that can lead by themselves to the diagnosis, otherwise impossible or very difficult with conventional MRI only. In these cases, once artifacts are excluded, additional or missing peaks discovered in the spectrum are of paramount importance.

Protocols for a practical approach to these diseases can vary according to each metabolic disorder, but are similar to the "general protocol" defined above: intermediate TE 2D-CSI $\mathrm{H}^{1} \mathrm{MRS}$ encompassing diseased brain and normal appearing tissue and short TE SVS (with offline metabolites analysis and quantification, if an advanced post-processing tool is available) centered in the largest visible lesion (if present). In case of diffuse brain alterations or no alteration detectable in conventional MRI, we suggest the evaluation of parietal lobe (see below), instead of frontal lobe, which has a physiologically high Cho content that can affect spectra interpretation (Figure $5 A, B$ ). If a mitochondrial disease is suspected, an intermediate TE 2D-CSI grid encompassing part of ventricular system is advised to detect the possible presence of CSF lactate.

Metabolic diseases in childhood are mostly congenital inborn errors of metabolism, whereas metabolic diseases in adults are more often acquired. Inborn errors of metabolism can result from single gene defects or from 
defects in enzymes or transport proteins, with the effect of accumulation of toxic substrates before the block, activation of alternative pathways and eventually failure of energy production and/or utilization. These defects can be classified biochemically (e.g., disorders of amino acid, carbohydrates, or fatty acid oxidation), or by cell main organelles dysfunction (mitochondria, lysosomes, peroxisomes) (146-148).

Organic acidemias, aminoacidopathies and mitochondrial disorders account for the majority of inborn errors of metabolism in newborns and infants. In $\mathrm{H}^{1} \mathrm{MRS}$ of organic acid disorders (e.g., propionic or methylmalonic acidemias), NAA reduction, along with elevation of Gln and Lac due to hyperammonemia, ketoacidosis and mitochondrial dysfunction, can be found (146-149). In the literature, there are single case reports of abnormal peaks resonating at 2.42 and in the $2.1-2.5 \mathrm{ppm}$ range, tentatively assigned to 3-OH-isovalerate and/or 3-OH-3-metilglutarate in 3-hydroxy-3-methylglutaric aciduria (150) and to $2 \mathrm{HG}$ in L-2-hydroxyglutaric aciduria respectively $(61,62)$ (Table 2).

Probably the most known pathognomonic $\mathrm{H}^{1} \mathrm{MRS}$ finding is that of Canavan disease ( $\mathrm{N}$-acetylaspartic aciduria), a disorder arising from a deficiency of the cytosolic enzyme aspartoacyclase found in oligodendrocytes (151), which gives rise to accumulation of NAA in brain parenchyma. $\mathrm{H}^{1}$ MRS shows marked elevation of the NAA peak and of $\mathrm{NAA} / \mathrm{Cr}$ ratio (152). Of note is the apparent increase of the NAA resonance at $2.02 \mathrm{ppm}$ reported in a free sialic acid (N-acetyl-neuraminic acid, NANA) storage disorder (i.e., Salla disease) $(17,153)$.

As regards aminoacidopathies, in nonketotic hyperglycinemia $(\mathrm{NKH})$, also known as glycine (Glyc) encephalopathy, a defect in the Glyc cleavage enzyme complex produces elevated concentrations of Glyc in organic fluids and in the brain. The neonatal form accounts for $85 \%$ of NKH patients: toxic effects of Glyc accumulation rapidly generate myelin vacuolation (restricted diffusion in DWI) (Figure 10A), demyelination and astrocytosis within posterior limbs of the internal capsule, cerebellar peduncles, dorsal midbrain, and pons, while unmyelinated areas are less affected. On short TE $\mathrm{H}^{1} \mathrm{MRS}$ performed at $1.5 \mathrm{~T}, \mathrm{~m}$-Ins and Glyc co-resonate at $~ 3.55-3.56 \mathrm{ppm}$ : since Glyc is a singlet (generated by two uncoupled co-resonating protons) and has a longer T2 value than $\mathrm{m}-\mathrm{Ins}$, intermediate (135-144 ms) (Figure 10C,D) or long (270-290 ms) echo times are needed for its identification (46,154-156).

In MSUD the altered metabolism of the essential amino acids leucine, isoleucine and valine leads to the accumulation of branched-chain amino acids (BCAA) and branched-chain $\alpha$-keto acids (BCKA); therefore, a complex peak, inverted only at intermediate TEs, in the 0.9-1 ppm range is detectable (65-67).

Phenylketonuria (PKU) is an aminoacidopathy in which Phenylalanine (Phe) accumulation is caused by an enzyme defect, leading to impaired brain development; early diagnosis is almost always made with the Guthrie test. The identification of the 7.3-ppm Phe multiplet with $\mathrm{H}^{1} \mathrm{MRS}$ is possible, but challenging: large VOI sampling and PRESS sequence with intermediate TE values are recommended $(157,158)$.

In sulfite oxidase deficiency and molybdenum cofactor deficiency, $\mathrm{H}^{1} \mathrm{MRS}$ (159), along with high Lac, tCho and Gln/ Glx levels (due to glutamate dehydrogenase inhibition by sulfites) and reduced NAA levels (160), additional abnormal peaks of sulfur-containing amino acids could be seen (i.e., Tau in the 3.2-3.4 ppm range, S-sulfocysteine at $\sim 3.6 \mathrm{ppm}$, and cysteine at $2.9 \mathrm{ppm}$ ) (161) (Figure 12C, Table 2).

In Urea cycle defects $(162,163)$, the most useful $\mathrm{H}^{1} \mathrm{MRS}$ finding is elevated Gln resulting from hyperammonemia.

As far as cell organelles dysfunctions are concerned, a prominent Lac peak (164) in brain and CSF due to decreased ATP production, albeit non-specific, is the major finding in the acute phase of the heterogeneous group of mitochondrial diseases (Figure 2B, Figure 7C, Figure 8 , Figure 13) (165-168); nevertheless, the lack of lactate doublet, particularly in the chronic phase, does not rule out the possibility of a mitochondrial dysfunction (169). Excess lactate/pyruvate can cause enhanced synthesis of Ala $(6,64,170,171)$ (Figure 13A,B,C). A nonspecific marked NAA reduction is frequently seen. Conversely, specific but exceptional findings are: in succinate dehydrogenase deficiency, a prominent succinate peak at $2.4 \mathrm{ppm}$ (172); in pyruvate dehydrogenase complex deficiency, an elevated pyruvate peak at $2.36 \mathrm{ppm}$ (167) (Table 2).

Also disorders primarily affecting white matter (leukoencephalopathies) have been classified in different ways (biochemically, by brain area of primary involvement, or by dysfunction of the primary subcellular organelles, etc.), and many of the above-mentioned metabolic diseases (e.g., Canavan disease) manifest as white matter abnormalities. $\mathrm{H}^{1} \mathrm{MRS}$ correlates of these disorders have been illustrated systematically elsewhere (173).

Bizzi et al. (174) have demonstrated that $\mathrm{H}^{1} \mathrm{MRS}$ can differentiate three main groups of childhood leukoencephalopathies by means of tCho/NAA, tCho/ 


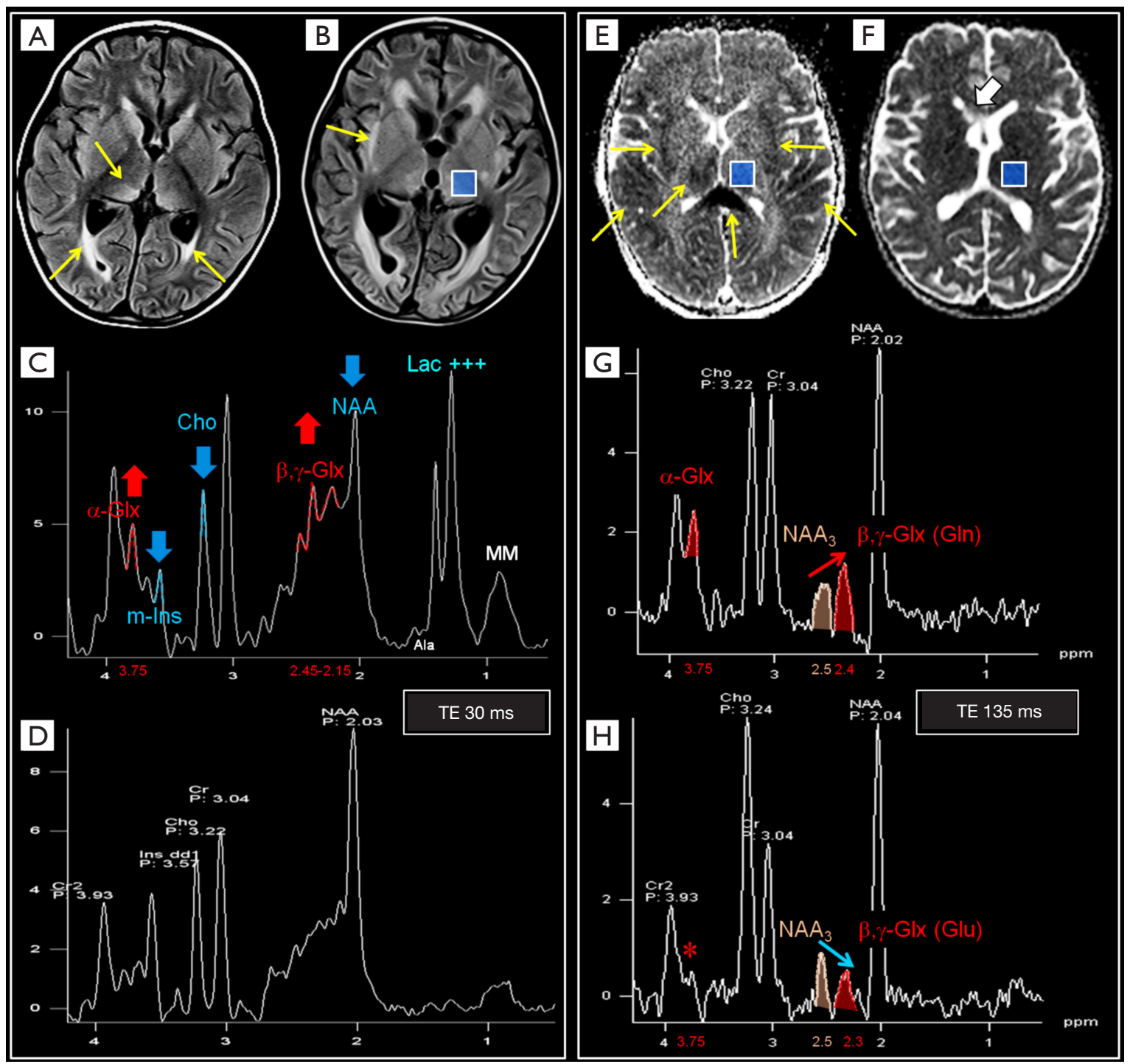

Figure 13 In left panel a previously healthy 6-year-old girl developing myoclonic seizures and progressive liver failure with a rapid worsening of the clinico-radiological picture is shown. FLAIR images obtained at 1 month (A) and at 3 months (B) follow-up show the progressive appearance of symmetric bilateral lesions in thalami, periventricular WM, and claustrum, along with diffuse atrophy. Short TE spectrum (C) acquired at 3 months follow-up, reveals the typical $\mathrm{H}^{1} \mathrm{MRS}$ pattern of hepatic encephalopathy: association of increased $\alpha, \beta, \gamma$-Glx peaks (due mainly to Gln, see red lines in LCModel post-processing of the same spectrum in Figure 4C) and decreased m-Ins and tCho levels; it is also associated a pattern of marked NAA decrease and pronounced Lac elevation (with slight Ala accumulation) suspect for a mitochondrial encephalopathy (see normal age-matched control spectrum in D for comparison). A diagnosis of Alpers-Huttenlocher syndrome was made; polymerase $\gamma$ (POLG1) gene sequencing documented a de novo heterozygous mutation not previously described. In right panel is shown an 8-year-old boy with a previous history of metastatic tumor in remission (small residual lesion indicated by white thick arrow in F) who developed repeated epileptic seizures, and rapidly fell into a coma after a flu-like syndrome. DWI ADC map (F) shows complete resolution after 2 weeks of diffuse cytotoxic edema in cerebral cortex, thalami and callosal splenium seen at presentation (yellow arrows in E). Intermediate TE spectra can give as well key clues to the diagnosis, finally made, of Reye syndrome due to salicylate therapy: abnormal $\alpha$-Glx peak at 3.75 ppm is visible also at this TE (G), in addition to reversal of normal $\mathrm{NAA}_{3} / \mathrm{Glx}$ ratio (thin red arrow in $\mathrm{G} ; \beta, \gamma-\mathrm{Glx}$ peak elevation at $\sim 2.4$ ppm due mainly to Gln). Normal NAA/Cr ratio restoration and $\mathrm{tCho} / \mathrm{Cr}$ elevation (explained with transient enhanced membrane turnover), along with disappearance of the $\alpha$-Glx peak (red asterisk in $\mathrm{H}$ ) and restoration of the normal $\mathrm{NAA}_{3} / \beta, \gamma-\mathrm{Glx}$ ratio (thin light blue arrow in $\mathrm{H} ; \beta, \gamma-\mathrm{Glx}$ main peak, due to Glu, centered at $\sim 2.3$ ppm) were seen after the patient nearly completely recovered. Acronyms and abbreviations are shown in Appendix 1. 
$\mathrm{Cr}$ and NAA/Cr ratios with an accuracy of $75 \%$ : actually, leukoencephalopathies can also be classified by pathological mechanisms including hypomyelination (quantitative deficit in myelin formation, with a tCho/ NAA ratio of $\sim 0.6$, e.g., Pelizaeus-Merzbacher disease and hypomyelination with hypogonadotropic hypogonadism and hypodontia, " $4 \mathrm{H}$ syndrome") (175), de/dysmyelination (loss/destruction of previously formed normal myelin or metabolic defect in myelin formation, with a tCho/ NAA ratio $>1.5$, e.g., metachromatic leukodystrophy, $\mathrm{X}$-linked adrenoleukodystrophy, Alexander disease, and Krabbe disease) (176), and white matter rarefaction (vacuolation or cystic degeneration of white matter tissue structure, replaced by CSF, with a tCho/NAA ratio of $\sim 1$, e.g., leukoencephalopathy with vanishing white matter). However, this evaluation is age-dependent (more reliable after 2 years of life) and attention should be paid also on voxel locations (examples are shown in Figure 14).

\section{Other rare genetic defects with pathognomonic $\mathbf{H}^{1}$ MRS patterns}

The occurrence of global NAA deficiency syndrome is anecdotic (177), while for males with autistic spectrum disorders clinicians often ask for $\mathrm{H}^{1} \mathrm{MRS}$ to rule out a $\mathrm{Cr}$ deficiency, despite its rarity. Conventional MRI in all the three known Cr deficiency syndromes (178) is almost noninformative, showing minimal or no pathologic findings; on the other hand, the absence of the two detectable $\mathrm{Cr}$ / PCr peaks at 3.2 and $3.9 \mathrm{ppm}$, with a normal pattern of the remaining metabolites, is pathognomonic for this disease. In guanidinoacetate methyltransferase (GAMT) syndrome an accumulation of guanidinoacetate (GAA, the immediate precursor of $\mathrm{Cr}$ ) at $\sim 3.8 \mathrm{ppm}$ can also be seen (179-181). Of note, in these patients the presence of a small "residual" peak at $3.0 \mathrm{ppm}$ at short TEs can be due do GABA and/or $\mathrm{MM}$, usually hidden by $\mathrm{Cr}_{1}$ resonance (6).

Galactosemia $(182,183)$ and other rare encephalopathies caused by different polyols accumulation (e.g., arabitol and ribitol) $(184,185)$ can be diagnosed by the identification of abnormal characteristic multiplets peaks with inversion at intermediate TEs in the 3.7-4 ppm range.

Other exceptional, but pathognomonic $\mathrm{H}^{1} \mathrm{MRS}$ findings in inherited disorders are listed in Table $2(186,187)$.

\section{Acquired pediatric metabolic and toxic disorders}

Among this group of diseases which can eventually result in similar clinical manifestations, hepatic encephalopathy (HE) shows a distinctive $\mathrm{H}^{1}$ MRS pattern, better seen in white matter $(6,188,189)$, but detectable in the whole brain (Figure 13).

HE comprises a broad spectrum of neurological disorders associated with liver diseases, ranging from viral infections to autoimmune and genetic conditions. The spectroscopic fingerprint of overt $\mathrm{HE}$ is the association of an increased Glx peak (mostly due to Glutamine, Gln) and decreased $\mathrm{m}$-Ins and Cho levels (due to osmolar adaptation for intraastrocytic accumulation of Gln) (190): Gln is synthesized in astrocytes from glutamate $(\mathrm{Glu})$ and ammonia $\left(\mathrm{NH}_{3}\right)$ and thus increased Gln in white matter correlates with increased plasma $\mathrm{NH}_{3}$ levels; isolated decrease of m-Ins can be found even in early subclinical phases $(39,188,189,191)$.

Reye's syndrome is usually characterized by a severe encephalopathy and visceral fatty degeneration in children following an infectious disease. About $90 \%$ of cases are associated with salicylate use. The above-mentioned specific spectral pattern is observed, with a marked increase of Gln and a substantial NAA preservation (Figure 13E,F,G,H) (192).

Also, other hepatocerebral syndromes usually show a similar pattern: e.g., Alpers-Huttenlocher syndrome, due to mitochondrial DNA depletion and mutations in polymerase $\gamma$ gene $(193,194)$, could be suspected in case of an association of elevate lactate peak, marked NAA reduction and classic hepatic encephalopathy MR spectrum; occasional Ala identification $(6,64)$ (Figure 13C) could be explained by excess Lac and/or by free ammonia enhanced transfer to pyruvate.

Two possible life-threatening complications of diabetes mellitus, also in children, are hyperglycemic hyperosmolar syndrome and diabetic ketoacidosis: in these cases, advanced post-processing softwares can help in the assignation of glucose peaks at 3.43 and $3.9 \mathrm{ppm}$ (Figure $4 A$ ) (195), and of ketone bodies peaks at $\sim 1.2$ and $\sim 2.2$ ppm $(6,75,196)$ (Table 2).

\section{Conclusions}

Knowledge of $\mathrm{H}^{1} \mathrm{MRS}$ is increasingly requested in clinical practice, and nowadays it should be part of the technical background also of pediatric neuroradiologists, as it can provide a unique tool to noninvasively investigate brain metabolism. Once the neuroradiologist has become familiar with its main artifacts, and with the specific spectroscopic features of the evolving child's brain, $\mathrm{H}^{1} \mathrm{MRS}$ can represent a valuable help for clinical issues, ranging from brain tumor prognosis to differential diagnosis in metabolic and genetic diseases. 

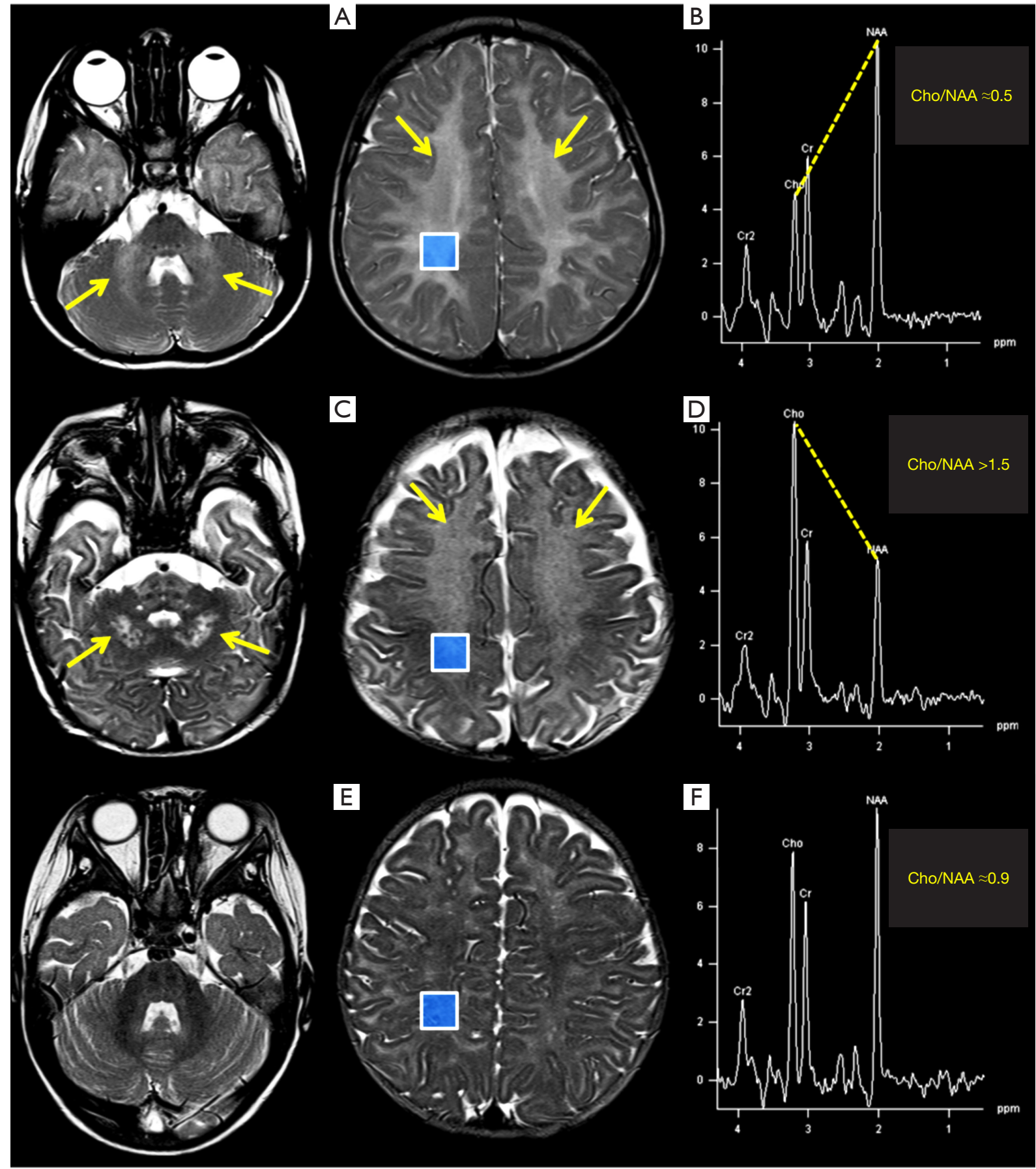

Figure 14 Top row: 4-year-old boy with ataxia as the main symptom, suffering from "4H syndrome" (hypomyelinating leukodystrophy) suspected by imaging first, with a confirmed novel mutation of POLR3A gene. MRI axial T2-WI (A): diffuse pathologic WM hyperintensities are evident (arrows pointing at middle cerebellar peduncles and centrum semiovale). The intermediate $\mathrm{TE}$ spectrum in the right parietal WM confirms that tCho/NAA $(\approx 0.5)$ and other metabolites ratios are within normal ranges for this age (B). Middle row: 5-month-old male with severe hypotonia and confirmed Krabbe disease (demyelinating leukodystrophy) showing pathological T2 hyperintensities in deep cerebellar WM and centrum semiovale with a typical "leopard skin" pattern (arrows in C). The spectrum in (D), obtained from the same area as those in (B) and (F), shows a tCho/NAA ratio > 1.5, abnormal even at this age. Bottom row: a 5-month-old female imaged for cryptogenic epilepsy is shown for comparison with case in (C): normal myelination $(\mathrm{E})$ and metabolites ratios $(\mathrm{tCho} / \mathrm{NAA} \approx 0.9)$ in parietal $\mathrm{WM}$ at this age $(\mathrm{F})$. Acronyms and abbreviations are shown in Appendix 1. 


\section{Acknowledgments}

We thank the colleagues from our Neuroradiology Unit, who contributed to the accomplishment of this paper, Dr. Francesca Branzoli, Sorbonne University, Paris, France, for her assistance with the LCModel analyses, Prof. Pietro Luigi Poliani, Pathology Unit, University of Brescia, Italy, for the pathological reports, and Dr. Domenico Zacà, University of Trento, Italy, for his technical support.

Funding: None.

\section{Footnote}

Provenance and Peer Review: This article was commissioned by the Guest Editor (Felice D'Arco) for the series "Pediatric Neuroradiology for Trainees and Fellows: An Updated Practical Guide" published in Translational Pediatrics. The article has undergone external peer review.

Conflicts of Interest: All authors have completed the ICMJE uniform disclosure form (available at http:// dx.doi.org/10.21037/tp-20-445). The series "Pediatric Neuroradiology for Trainees and Fellows: An Updated Practical Guide" was commissioned by the editorial office without any funding or sponsorship. The authors have no other conflicts of interest to declare.

Ethical Statement: The authors are accountable for all aspects of the work in ensuring that questions related to the accuracy or integrity of any part of the work are appropriately investigated and resolved.

Open Access Statement: This is an Open Access article distributed in accordance with the Creative Commons Attribution-NonCommercial-NoDerivs 4.0 International License (CC BY-NC-ND 4.0), which permits the noncommercial replication and distribution of the article with the strict proviso that no changes or edits are made and the original work is properly cited (including links to both the formal publication through the relevant DOI and the license). See: https://creativecommons.org/licenses/by-nc-nd/4.0/.

\section{References}

1. Dou W, Zhang M, Zhang X, et al. Convex-Envelope Based Automated Quantitative Approach to Multi-Voxel 1 H-MRS Applied to Brain Tumor Analysis. PLoS One 2015;10:e0137850.
2. Mescher M, Merkle H, Kirsch J, et al. Simultaneous in vivo spectral editing and water suppression. NMR Biomed 1998;11:266-72.

3. Robertson NJ, Cox IJ. Magnetic resonance spectroscopy of the neonatal brain. In: Rutherford MA (ed). MRI of the Neonatal Brain. 4th edition. WB Saunders, London, 2002:295-313.

4. Annink KV, van der Aa NE, Dudink J, et al. Introduction of Ultra-High-Field MR Imaging in Infants: Preparations and Feasibility. AJNR Am J Neuroradiol 2020;41:1532-7.

5. Kousi E, Tsougos I, Eftychia K. Proton magnetic resonance spectroscopy of the central nervous system. Novel Frontiers of Advanced Neuroimaging. InTech, 2013;19-50.

6. Danielsen ER, Ross B. Magnetic Resonance Spectroscopy Diagnosis of Neurological Diseases. New York: Marcel Dekker, Inc., 1999.

7. Govindaraju V, Young K, Maudsley AA. Proton NMR chemical shifts and coupling constants for brain metabolites. NMR Biomed 2000;13:129-53.

8. Bagby S. J Coupling. In: Roberts GCK. (eds) Encyclopedia of Biophysics. Berlin, Heidelberg: Springer, 2013;1163-8.

9. Kelley DA, Wald LL, Star-Lack JM. Lactate detection at 3T: compensating J coupling effects with BASING. J Magn Reson Imaging 1999;9:732-7.

10. Panigrahy A, Nelson MD, Blüml S. Magnetic resonance spectroscopy in pediatric neuroradiology: clinical and research applications. Pediatr Radiol 2010;40:3-30.

11. ACR-ASNR-SPR Practice Parameter for the Performance and Interpretation of Magnetic Resonance (MR) Spectroscopy of the Central Nervous System Res. Available online: https://www.asnr.org/guidelinesstandards/acr-asnr-spr-practice-parameter-for-theperformance-and-interpretation-of-magnetic-resonancemr-spectroscopy-of-the-central-nervous-systemres-7-2013-amended-2014-res-3/

12. Lin M, Kumar A, Yang S. Two-dimensional J-resolved LASER and semi-LASER spectroscopy of human brain. Magn Reson Med 2014;71:911-20.

13. Andronesi OC, Rapalino O, Gerstner E, et al. Detection of oncogenic IDH1 mutations using magnetic resonance spectroscopy of 2-hydroxyglutarate. J Clin Invest 2013;123:3659-63.

14. Branzoli F, Di Stefano AL, Capelle L, et al. Highly specific determination of IDH status using edited in vivo magnetic resonance spectroscopy. Neuro Oncol 2018;20:907-16.

15. Lange T, Dydak U, Roberts TP, et al. Pitfalls in lactate measurements at $3 \mathrm{~T}$. AJNR Am J Neuroradiol 
2006;27:895-901.

16. Blüml S. Magnetic Resonance Spectroscopy: Basics. In: Blüml S, Panigrahy A (eds). MR Spectroscopy of Pediatric Brain Disorders. New York: Springer-Verlag, 2013:11-24.

17. Barker PB, Bizzi A, De Stefano N, et al. Clinical Mr Spectroscopy. Techniques and Applications. New York: Cambridge University Press, 2010.

18. Danielsen ER, Henriksen O. Absolute quantitative proton NMR spectroscopy based on the amplitude of the local water suppression pulse. Quantification of brain water and metabolites. NMR Biomed 1994;7:311-8.

19. Kreis R. Quantitative localized $1 H$ MR spectroscopy for clinical use. Prog NMR Spectrosc 1997;31:155-95.

20. Dezortova M, Hajek M. 1 H MR spectroscopy in pediatrics. Eur J Radiol 2008;67:240-9.

21. Pouwels PJ, Brockmann K, Kruse B, et al: Regional age dependence of human brain metabolites from infancy to adulthood as detected by quantitative localized proton MRS. Pediatr Res 1999;46:474-85.

22. Cichocka M, Kozub J, Karcz P, et al. Regional differences in the concentrations of metabolites in the brain of healthy children: A proton magnetic resonance spectroscopy (1HMRS) Study. Pol J Radiol 2016;81:473-7.

23. Brandao AL, Domingues RC. MR Spectroscopy of the Brain. Philadelphia: Lippincott Williams \& Wilkins, 2004:10-1.

24. Juchem C, De Graaf RA. B0 magnetic field homogeneity and shimming for in vivo magnetic resonance spectroscopy. Anal Biochem 2017;529:17-29.

25. Kreis R. Issues of spectral quality in clinical $1 \mathrm{H}$-magnetic resonance spectroscopy and a gallery of artifacts. NMR Biomed 2004;17:361-81.

26. Wilson M, Andronesi O, Barker PB, et al. Methodological consensus on clinical proton MRS of the brain: Review and recommendations Magn Reson Med 2019;82:527-50.

27. Ladd ME, Bachert O, Meyerspeer M, et al. Pros and cons of ultra-high-field MRI/MRS for human application. Prog Nucl Magn Reson Spectrosc 2018;109:1-50.

28. Cecil KM. Proton magnetic resonance spectroscopy: technique for the neuroradiologist. Neuroimaging Clin $\mathrm{N}$ Am 2013;23:381-92.

29. Smith JK, Kwock L, Castillo M. Effects of contrast material on single-volume proton MR spectroscopy. AJNR Am J Neuroradiol 2000;21:1084-9.

30. Barker PB. N-acetyl-aspartate-a neuronal marker? Ann Neurol 2001;49:423-4.

31. Baslow MH. Functions of $\mathrm{N}$-acetyl-L-aspartate and Nacetyl-aspartylglutamate in the vertebrate brain: role in glial cell-specific signaling. J Neurochem 2000;75:453-9.

32. Tallan HH. Studies on the distribution of $\mathrm{N}$-acetylLaspartic acid in brain. J Biol Chem 1957;224:41-5.

33. Kreis R, Ernst T, Ross BD. Development of the human brain: in vivo quantification of metabolite and water content with proton magnetic resonance spectroscopy. Magn Reson Med 1993;30:424-37.

34. Blüml S, Seymour KJ, Ross BD. Developmental changes in choline- and ethanolamine-containing compounds measured with proton-decoupled (31)P MRS in in vivo human brain. Magn Reson Med 1999;42:643-54.

35. Lien YH, Shapiro JI, Chan L. Effects of hypernatremia on organic brain osmoles. J Clin Invest 1990;85:1427-35.

36. Pfefferbaum A, Adalsteinsson E, Spielman D, et al. In vivo spectroscopic quantification of the $\mathrm{N}$-acetyl moiety, creatine, and choline from large volumes of brain gray and white matter: effects of normal aging. Magn Reson Med 1999;41:276-84.

37. Hattingen E, Raab P, Franz K, et al. Myo-Inositol: a marker of reactive astrogliosis in glial tumors? NMR Biomed 2008;21:233-41.

38. Videen JS. Human cerebral osmolytes during chronic hyponatremia. A proton magnetic resonance spectroscopy study. J Clin Invest 1995;95:788-93.

39. Ross BD, Jacobson S, Villamil F, et al. Subclinical hepatic encephalopathy: proton MR spectroscopic abnormalities. Radiology 1994;193:457-63.

40. Provencher SW. Estimation of metabolite concentrations from localized in vivo proton NMR spectra. Magn Reson Med 1993;30:672-9.

41. Provencher SW. Automatic quantitation of localized in vivo $1 \mathrm{H}$ spectra with LCModel. NMR Biomed 2001;14:260-4.

42. Stefan D, Cesare F, Andrasescu A, et al. Quantitation of magnetic resonance spectroscopy signals: the jMRUI software package. Meas Sci Technol 2009;20:104035.

43. Wilson M, Reynolds G, Kauppinen RA, et al. A constrained leastsquares approach to the automated quantitation of in vivo $1 \mathrm{H}$ magnetic resonance spectroscopy data. Magn Reson Med 2011;65:1-12.

44. Schulte RF, Boesiger P. ProFit: two-dimensional priorknowledge fitting of Jresolved spectra. NMR Biomed 2006;19:255-63.

45. Purvis LAB, Clarke WT, Biasiolli L, et al. OXSA: an opensource magnetic resonance spectroscopy analysis toolbox in MATLAB. PLoS One 2017;12:e0185356.

46. Mullins PG, McGonigle DJ, O'Gorman RL, et al. Current practice in the use of MEGA-PRESS spectroscopy for the 
detection of GABA. Neuroimage 2014;86:43-52.

47. Kreis R. Metabolic disorders of the brain in chronic hepatic encephalopathy detected with H-1 MR spectroscopy. Radiology 1992;182:19-27.

48. Robertson NJ, Kuint J, Counsell SJ, et al. Characterization of cerebral white matter damage in preterm infant using $1 \mathrm{H}$ and $31 \mathrm{P}$ magnetic resonance spectroscopy. J Cereb Blood Flow Metab 2000;20:1446-56.

49. Seeger U, Klose U, Mader I, et al. Parameterized Evaluation of Macromolecules and Lipids in Proton MR Spectroscopy of Brain Diseases. Magn Reson Med 2003;49:19-28.

50. Hofmann L, Slotboom J, Boesch C, et al. Characterization of the macromolecule baseline in localized 1H-MR spectra of human brain. Magn Reson Med 2001;46:855-63.

51. Napolitano A, Savvopoulos F, Jaspan T, et al. Proton spectroscopy for lipid characterisation in paediatric brain tumours. Proc Intl Soc Mag Reson Med 2011;19:4268.

52. Kreis R, Hofmann L, Kuhlmann B, et al. Brain metabolite composition during early human brain development as measured by quantitative in vivo $1 \mathrm{H}$ magnetic resonance spectroscopy. Magn Reson Med 2002;48:949-58.

53. Kovanlikaya A, Panigrahy A, Krieger MD, et al. Untreated pediatric primitive neuroectodermal tumor in vivo: quantitation of taurine with MR spectroscopy. Radiology 2005;236:1020-5.

54. Moreno-Torres A, Martinez-Perez I, Baquero M, et al. Taurine detection by proton magnetic resonance spectroscopy in medulloblastoma: contribution to noninvasive differential diagnosis with cerebellar astrocytomas. Neurosurgery 2004;5 5:824-9.

55. Panigrahy A, Krieger M, Gonzalez-Gomez I, et al. Quantitative short echo time $1 \mathrm{H}$ magnetic resonance spectroscopy of untreated pediatric brain tumors: preoperative diagnosis and characterization. AJNR Am J Neuroradiol 2006;27:560-72.

56. Manley BJ, Sokol J, Cheong JL. Intracerebral blood and MRS in neonatal nonketotic hyperglycinemia. Pediatr Neurol 2010;42:219-22.

57. Davies NP, Wilson M, Natarajan K, et al. Non-invasive detection of glycine as a biomarker of malignancy in childhood brain tumours using in-vivo $1 \mathrm{H}$ MRS at 1.5 Tesla confirmed by ex-vivo high-resolution magic-angle spinning NMR. NMR Biomed 2010;23:80-7.

58. Carapella CM, Carpinelli G, Knijn A, et al. Potential role of in vitro $1 \mathrm{H}$ magnetic resonance spectroscopy in the definition of malignancy grading of human neuroepithelial brain tumours. Acta Neurochir Suppl 1997;68:127-32.
59. Lehnhardt FG, Röhn G, Ernestus RI, et al. 1 H- and (31) P-MR spectroscopy of primary and recurrent human brain tumors in vitro: malignancy-characteristic profiles of water soluble and lipophilic spectral components. NMR Biomed 2001;14:307-17.

60. Choi C, Ganji SK, DeBerardinis RJ, et al.

2-hydroxyglutarate detection by magnetic resonance spectroscopy in IDH-mutated patients with gliomas. Nat Med 2012;18:624-9.

61. Aydin K, Ozmen M, Tatli B, et al. Single-voxel MR spectroscopy and diffusion-weighted MRI in two patients with 1-2-hydroxyglutaric aciduria. Pediatr Radiol 2003;33:872-6.

62. Sener RN. L-2 hydroxyglutaric aciduria: proton magnetic resonance spectroscopy and diffusion magnetic resonance imaging findings. J Comput Assist Tomogr 2003;27:38-43.

63. Tugnoli V, Schenetti L, Mucci A, et al. Ex vivo HR-MAS MRS of human meningiomas: a comparison with in vivo 1H MR spectra. Int J Mol Med 2006;18:859-69.

64. Waagepetersen HS, Sonnewald U, Larsson OM, et al. A possible role of alanine for ammonia transfer between astrocytes and glutamatergic neurons. J Neurochem 2000;75:471-9.

65. Jan W, Zimmerman RA, Wang ZJ, et al. MR diffusion imaging and MR spectroscopy of maple syrup urine disease during acute metabolic decompensation. Neuroradiology 2003;45:393-9.

66. Cavalleri F, Bernardi A, Burlina A, et al. Diffusionweighted MRI of maple syrup urine disease encephalopathy. Neuroradiology 2002;44:499-502.

67. Sener RN. Maple syrup urine disease: diffusion MRI, and proton MR spectroscopy findings. Comput Med Imaging Graph 2007;31:106-10.

68. Garg M, Gupta RK, Husain M, et al. Brain abscesses: etiologic categorization with in vivo proton $\mathrm{MR}$ spectroscopy. Radiology 2004;230:519-27.

69. Pal D, Bhattacharyya A, Husain M, et al. In vivo proton MR spectroscopy evaluation of pyogenic brain abscesses: a report of 194 cases. AJNR Am J Neuroradiol 2010;31:360-6.

70. Gupta RK, Jobanputra KJ, Yadav A. MR spectroscopy in brain infections. Neuroimaging Clin N Am 2013;23:475-98.

71. Oakden WK, Noseworthy MD. Propylene glycol is essential in the LCModel basis set for pediatric 1H-MRS. J Comput Assist Tomogr 2005;29:136-9.

72. Cady EB, Lorek A, Penrice J, et al. Detection of propan1,2-diol in neonatal brain by in vivo proton magnetic resonance spectroscopy. Magn Reson Med 1994;32:764-7. 
73. Du F, Zhang Y, Iltis I, et al. In vivo proton MRS to quantify anesthetic effects of pentobarbital on cerebral metabolism and brain activity in rat. Magn Reson Med 2009;62:1385-93.

74. Kim JY, Ahn K, Yu WJ, et al. Mannitol as a Potential Pitfall for Peak Assignment on Magnetic Resonance Spectra (MRS) for Brain Tumors: A Case Report. J Korean Soc Radiol 2009;60:373-6.

75. Seymour KJ, Bluml S, Sutherling J, et al. Identification of cerebral acetone by $1 \mathrm{H}-\mathrm{MRS}$ in patients with epilepsy controlled by ketogenic diet. MAGMA 1999;8:33-42.

76. Cecil KM, Lin A, Ross BD, et al. Methylsulfonylmethane observed by in vivo proton magnetic resonance spectroscopy in a 5-year-old child with developmental disorder: effects of dietary supplementation. J Comput Assist Tomogr 2002;26:818-20.

77. Wilke M, Eidenschink A, Muller-Weihrich S, et al. MR diffusion imaging and $1 \mathrm{H}$ spectroscopy in a child with medulloblastoma. A case report. Acta Radiol 2001;42:39-42.

78. Tong $Z$, Yamaki T, Harada $\mathrm{K}$, et al. In vivo quantification of the metabolites in normal brain and brain tumors by proton MR spectroscopy using water as an internal standard. Magn Reson Imaging 2004;22:1017-24.

79. Koeller KK, Rushing EJ. Medulloblastoma: Comprehensive review with radiologic-Pathologic correlation. Radiographics 2003;23:1613-37.

80. Juraschka K, Taylor MD. Medulloblastoma in the age of molecular subgroups: a review: JNSPG 75th Anniversary Invited Review Article. J Neurosurg Pediatr 2019;24:353-63.

81. Dangouloff-Ros V, Varlet P, Levy R, et al. Imaging features of medulloblastoma: conventional imaging, diffusion-weighted imaging, perfusion-weighted imaging, and spectroscopy: from general features to subtypes and characteristics. Neurochirurgie 2021;67:6-13.

82. Perreault S, Ramaswamy V, Achrol AS, et al. MRI surrogates for molecular subgroups of medulloblastoma. AJNR Am J Neuroradiol 2014;35:1263-9.

83. D'Arco F, Khan F, Mankad K, et al. Differential diagnosis of posterior fossa tumours in children: new insights. Pediatr Radiol 2018;48:1955-63.

84. Gill SK, Panigrahy A, Arvanitis TN, et al. Magnetic Resonance Spectroscopy of Pediatric Brain Tumors. In: Blüml S, Panigrahy A (eds). MR Spectroscopy of Pediatric Brain Disorders. New York: Springer-Verlag, 2013:45-60.

85. Vicente J, Fuster-Garcia E, Tortajada S, et al. Accurate classification of childhood brain tumours by in vivo $1 \mathrm{H}$ MRS-a multi-centre study. Eur J Cancer 2013;49:658-667.
86. Schneider JF, Viola A, Confort-Gouny S, et al. Infratentorial pediatric brain tumors: the value of new imaging modalities. J Neuroradiol 2007;34:49-58.

87. Blüml S, Panigrahy A. Case Reports. In: Blüml S, Panigrahy A (eds). MR Spectroscopy of Pediatric Brain Disorders. New York: Springer-Verlag, 2013:307-87.

88. Makola M, Cecil KM. Dysembryoplastic neuroepithelial tumor (DNET) and focal cortical dysplasia: case report of two pediatric patients with imaging features. Inter J Diagnostic Imag 2017;4:31-8.

89. Malmer B, Iselius L, Holmberg E, et al. Genetic epidemiology of glioma. Br J Cancer 2001;84:429-34.

90. Farrell CJ, Plotkin SR. Genetic causes of brain tumors: neurofibromatosis, tuberous sclerosis, von Hippel-Lindau, and other syndromes. Neurol Clin 2007;25:925-46.

91. Ryall S, Tabori U, Hawkins C. Pediatric low-grade glioma in the era of molecular diagnostics. Acta Neuropathol Commun 2020;8:30.

92. Cohen AL, Holmen SL, Colman H. IDH1 and IDH2 mutations in gliomas. Curr Neurol Neurosci Rep 2013;13:345.

93. Paugh BS, Qu C, Jones C, et al. Integrated molecular genetic profiling of pediatric high-grade gliomas reveals key differences with the adult disease. J Clin Oncol 2010;28:3061-8.

94. Pollack IF, Hamilton RL, Sobol RW, et al. IDH1 mutations are common in malignant gliomas arising in adolescents: a report from the Children's Oncology Group. Childs Nerv Syst 2011;27:87-94.

95. Molinaro AM, Taylor JW, Wiencke JK, et al. Genetic and molecular epidemiology of adult diffuse glioma. Nat Rev Neurol 2019;15:405-17.

96. Castillo M, Smith JK, Kwock L. Correlation of myoinositol levels and grading of cerebral astrocytomas. AJNR Am J Neuroradiol 2000;21:1645-9.

97. Tzika AA, Vigneron DB, Dunn RS, et al. Intracranial tumors in children: small single-voxel proton MR spectroscopy using short- and long-echo sequences. Neuroradiology 1996;38:254-63.

98. Negendank W. Studies of human tumors by MRS: a review. NMR Biomed 1992;5:303-24.

99. Negendank WG, Sauter R, Brown TR, et al. Proton magnetic resonance spectroscopy in patients with glial tumors: a multicenter study. J Neurosurg 1996;84:449-58.

100.Nelson SJ, Vigneron DB, Dillon WP. Serial evaluation of patients with brain tumors using volume MRI and 3D $1 \mathrm{H}$ MRSI. NMR Biomed 1999;12:123-38.

101.Sijens PE, Knopp MV, Brunetti A, et al. 1H MR 
spectroscopy in patients with metastatic brain tumors: a multicenter trial. Magn Reson Med 1995;33:818-26.

102. Taylor JS, Ogg RJ, Langston JW. Proton MR spectroscopy of pediatric brain tumors. Neuroimaging Clin N Am 1998;8:753-79.

103. Taylor JS, Langston JW, Reddick WE, et al. Clinical value of proton magnetic resonance spectroscopy for differentiating recurrent or residual brain tumor from delayed cerebral necrosis. Int J Radiat Oncol Biol Phys 1996;36:1251-61.

104. Shimizu H, Kumabe T, Tominaga T, et al. Noninvasive evaluation of malignancy of brain tumors with proton MR spectroscopy. AJNR Am J Neuroradiol 1996;17:737-47.

105. Tedeschi G, Lundbom N, Raman R, et al. Increased choline signal coinciding with malignant degeneration of cerebral gliomas: a serial proton magnetic resonance spectroscopy imaging study. J Neurosurg 1997;87:516-24.

106. Setzer M, Herminghaus S, Marquardt G, et al. Diagnostic impact of proton MR-spectroscopy versus image-guided stereotactic biopsy. Acta Neurochir (Wien) 2007:149:379-86.

107.Lazareff JA, Gupta RK, Alger J. Variation of posttreatment H-MRSI choline intensity in pediatric gliomas. J Neurooncol 1999;41:291-8.

108. Warren KE, Frank JA, Black JL, et al. Proton magnetic resonance spectroscopic imaging in children with recurrent primary brain tumors. J Clin Oncol 2000;18:1020-6.

109. Tzika AA, Astrakas LG, Zarifi MK, et al. Spectroscopic and perfusion magnetic resonance imaging predictors of progression in pediatric brain tumors. Cancer 2004;100:1246-56.

110.Wald LL, Nelson SJ, Day MR, et al. Serial proton magnetic resonance spectroscopy imaging of glioblastoma multiforme after brachytherapy. J Neurosurg 1997;87:525-34.

111.Preul MC, Leblanc R, Caramanos Z, et al. Magnetic resonance spectroscopy guided brain tumor resection: differentiation between recurrent glioma and radiation change in two diagnostically difficult cases. Can J Neurol Sci 1998;25:13-22.

112. Isobe T, Matsumura A, Anno I, et al. Changes in 1H-MRS in glioma patients before and after irradiation: the significance of quantitative analysis of choline-containing compounds. No Shinkei Geka 2003;31:167-72.

113. Schlemmer HP, Bachert P, Herfarth KK, et al. Proton MR spectroscopic evaluation of suspicious brain lesions after stereotactic radiotherapy. AJNR Am J Neuroradiol 2001;22:1316-24.
114.Zhang H, Ma L, Wang Q, et al. Role of magnetic resonance spectroscopy for the differentiation of recurrent glioma from radiation necrosis: a systematic review and meta-analysis. Eur J Radiol 2014;83:2181-9.

115.Sundgren PC. MR spectroscopy in radiation injury. AJNR Am J Neuroradiol 2009;30:1469-76.

116. Bernabeu A, López-Celada S, Alenda C, et al. Epidermoid cyst with a metabolite pattern mimicking a brain abscess.

A magnetic resonance spectroscopy study. J Neuroimaging 2013;23:145-8.

117.von Koch CS, Young G, Chin CT, et al. Magnetic resonance imaging/spectroscopy of an intraaxial epidermoid: similarity to an abscess: Case illustration. J Neurosurg 2002;97:492.

118. Saindane AM, Cha S, Law M, et al. Proton MR spectroscopy of tumefactive demyelinating lesions. AJNR Am J Neuroradiol 2002;23:1378-86.

119. Mader I, Wolff M, Nägele T, et al. MRI and proton MR spectroscopy in acute disseminated encephalomyelitis. Childs Nerv Syst 2005;21:566-72.

120.Panigrahy A, Krieger M, Gonzalez-Gomez I, et al. Differentiation of encephalitis from astrocytomas in pediatric patients by quantitative in vivo MR spectroscopy. Abstract. Chicago: ASNR, 2007.

121.Sämann PG, Schlegel J, Müller G, et al. Serial proton MR spectroscopy and diffusion imaging findings in HIV-related herpes simplex encephalitis. AJNR Am J Neuroradiol 2003;24:2015-19.

122.Hassell KJ, Ezzati M, Alonso-Alconada D et al. New horizons for newborn brain protection: enhancing endogenous neuroprotection. Arch Dis Child Fetal Neonatal Ed 2015;100:F541-52.

123.Zarifi MK, Astrakas LG, Poussaint TY, et al. Prediction of adverse outcome with cerebral lactate level and apparent diffusion coefficient in infants with perinatal asphyxia. Radiology 2002;225:859-70.

124. Barkovich AJ, Miller SP, Bartha A, et al. MR imaging, MR spectroscopy, and diffusion tensor imaging of sequential studies in neonates with encephalopathy. AJNR Am J Neuroradiol 2006;27:533-47.

125. Holshouser BA, Ashwal S, Luh GY, et al. Proton MR spectroscopy after acute central nervous system injury: outcome prediction in neonates, infants, and children. Radiology 1997;202:487-96.

126. Penrice J, Cady EB, Lorek A, et al. Proton magnetic resonance spectroscopy of the brain in normal and term infants and early changes after perinatal hypoxia-ischemia. Pediatr Res 1996;40:6-14. 
127. Leth H, Toft PB, Peitersen B, et al. Use of brain lactate levels to predict outcome after perinatal asphyxia. Acta Paediatr 1996;85:859-64.

128. Groenendaal F, Veenhoven RH, van der Grond J, et al. Cerebral lactate and $\mathrm{N}$-acetyl-aspertate/choline ratios in asphyxiated full term neonates demonstrated in-vivo using proton magnetic resonance spectroscopy. Pediatr Res 1994;35:148-51.

129. Cheong JL, Cady EB, Penrice J, et al. Proton MR spectroscopy in neonates with perinatal cerebral hypoxic ischemic injury: metabolite peak-area ratios, relaxation times, and absolute concentrations. AJNR Am J Neuroradiol 2006;27:1546-54.

130. Barkovich AJ, Baranski K, Vigneron DB, et al. Proton MR spectroscopy for the evaluation of asphyxiated term neonates. AJNR Am J Neuroradiol 1999;20:1399-405.

131. Vigneron DB, Barkovich AJ, Noworolski SM, et al, Threedimensional proton MR spectroscopic imaging of premature and term neonates. AJNR Am J Neuroradiol 2001;22:1424-33.

132. Shanmugalingam S, Thorton JS, Iwata O, et al. Comparative prognostic utilities of early quatitative magnetic resonance imaging spin-spin relaxaometry and proton magnetic resonance spectroscopy in neonatal encephalopathy. Pediatrics 2006;118:1467-77.

133.Roelants-Van Rijn AM, van der Grond J, de Vries LS, et al. Value of (1) H-MRS using different echo times in neonates with cerebral hypoxia-ischemia. Pediatr Res 2001;49:356-62.

134. L'Abee C, de Vries LS, van der Grond J, et al. Early diffusion-weighted MRI and 1H-Magnetic Resonance Spectroscopy in asphyxiated full-term neonates. Biol Neonate 2005;88:306-12.

135. Robertson NJ, Lewis RH, Cowan FM, et al. Early increases in brain myo-inositol measured by proton magnetic resonance spectroscopy in term infants with neonatal encephalopathy. Pediatr Res 2001;50:692-700.

136. Brissaud O, Chateil JF, Bordessoules M, et al. Chemical shift imaging and localized magnetic resonance spectroscopy in full term asphyxiated neonates. Pediatr Radiol 2005;35:998-1005.

137. Meyer-Witte S, Brissaud O, Brun M, et al. Prognostic value of MR in term neonates with neonatal hypoxicischemic encephalopathy: MRI score and spectroscopy. About 26 cases. Arch Pediatr 2008;15:9-23.

138. Brown M, Baradaran H, Christos PJ, et al. Magnetic resonance spectroscopy abnormalities in traumatic brain injury: A meta-analysis. J Neuroradiol 2018;45:123-9.
139. Haseler LJ, Arcinue E, Danielsen ER, et al. Evidence from proton magnetic resonance spectroscopy for a metabolic cascade of neuronal damage in shaken baby syndrome. Pediatrics 1997;99:4-14.

140. Condon B, Oluoch-Olunya D, Hadley D, et al. Early $1 \mathrm{H}$ magnetic resonance spectroscopy of acute head injury: four cases. J Neurotrauma 1998;15:563-71.

141. Holshouser BA, Ashwal S, Shu S, et al. Proton MR spectroscopy in children with acute brain injury: comparison of short and long echo time acquisitions. J Magn Reson Imaging 2000;11:9-19.

142. Ross BD, Ernst T, Kreis R, et al. 1H MRS in acute traumatic brain injury. J Magn Reson Imaging 1998;8:829-40.

143. Govindaraju V, Gauger GE, Manley GT, et al. Volumetric proton spectroscopic imaging of mild traumatic brain injury. AJNR Am J Neuroradiol 2004;25:730-7.

144.Jope RS, Jenden DJ. Choline and phospholipid metabolism and the synthesis of acetylcholine in rat brain. J Neurosci Res 1979;4:69-82.

145. Miller BL. A review of chemical issues in $1 \mathrm{H} \mathrm{NMR}$ spectroscopy: $\mathrm{N}$-acetyl-L-aspartate, creatine and choline. NMR Biomed 1991;4:47-52.

146. Barkovich AJ. Toxic and metabolic brain disorders. In: Barkovich AJ (ed) Pediatric neuroimaging, 4th ed. Philadelphia: Lippincott Williams \& Wilkins, 2005:76-189.

147. Cecil K. MR spectroscopy of metabolic disorders. In: Castillo M, Mukherji SK (eds). Neuroimaging clinics of North America, volume 16, number 1. Philadelphia: Saunders, 2006:87-116.

148.van der Knaap MS, Valk J. Magnetic resonance of myelin, myelination and myelin disorders, 2nd ed. Berlin: Springer, 1995.

149.Enns GM, Barkovich AJ, Rosenblatt DS, et al. Progressive neurological deterioration and MRI changes in cblC methylmalonic academia treated with hydroxocoblamin. J Inherit Metab Dis 1999;22:599-607.

150. Yalçinkaya C, Dinçer A, Gündüz E, et al. MRI and MRS in HMG-CoA lyase deficiency. Pediatr Neurol 1999;20:375-80.

151.Madhavarao CN, Moffett JR, Moore RA, et al. Immunohistochemical localization of aspatoacylase in the rat central nervous system. J Comp Neurol 2004;472:318-29.

152. Barker PB, Bryan RN, Kumar AJ, et al. Proton NMR spectroscopy of Canavan's disease. Neuropediatrics 1992;23:263-7.

153. Varho T, Komu M, Sonninen P, et al. A new metabolite 
contributing to $\mathrm{N}$-acetyl signal in $1 \mathrm{H}$ MRS of the brain in Salla disease. Neurology 1999;52:1668-72.

154. Choi CG, Lee HK, Yoon JH. Localized proton MR spectroscopic detection of nonketotic hyperglycinemia in an infant. Korean J Radiol 2001;2:239-42.

155. Gabis L, Parton $\mathrm{P}$, Roche $\mathrm{P}$, et al. In vivo $1 \mathrm{H}$ magnetic resonance spectroscopic measurement of brain glycine levels in nonketotic hyperglycinemia. J Neuroimaging 2001;11:209-11.

156. Shah DK, Tingay DG, Fink AM, et al. Magnetic resonance imaging in neonatal nonketotic hyperglycinemia. Pediatr Neurol 2005;33:50-2.

157.Sijens PE, Oudkerk M, Reijngoud DJ, et al. $1 \mathrm{H} \mathrm{MR}$ chemical shift imaging detection of phenylalanine in patients suffering from phenylketonuria (PKU). Eur Radiol 2004;14:1895-900.

158.Leuzzi V, Bianchi MC, Tosetti M, et al. Clinical significance of brain phenylalanine concentration assessed by in vivo proton magnetic resonance spectroscopy in phenylketonuria. J Inherit Metab Dis 2000;23:563-70.

159. Reddy N, Calloni SF, Vernon HJ, et al. Neuroimaging findings of organic acidemias and aminoacidopathies. Radiographics 2018;38:912-31.

160.Eichler F, Tan WH, Shih VE, et al. Proton magnetic resonance spectroscopy and diffusion-weighted imaging in isolated sulfite oxidase deficiency. J Child Neurol 2006;21:801-5.

161.Hoffmann C, Ben-Zeev B, Anikster Y, et al. Magnetic resonance imaging and magnetic resonance spectroscopy in isolated sulfite oxidase deficiency. J Child Neurol 2007;22:1214-21.

162. Takanashi J, Barkovich A, Cheng S, et al. Brain MR imaging in acute hyperammonemic encephalopathy arising from late-onset ornithine transcarbamylase deficiency. AJNR Am J Neuroradiol 2003;24:390-3.

163. Choi CG, Yoo HW. Localized proton MR spectroscopy in infants with urea cycle defect. AJNR Am J Neuroradiol 2001;22:834-7.

164.Lunsing RJ, Strating K, de Koning TJ, et al. Diagnostic value of MRS-quantified brain tissue lactate level in identifying children with mitochondrial disorders. Eur Radiol 2017;27:976-84.

165. Bianchi MC, Tosetti M, Battini R, et al. Proton MR spectroscopy of mitochondrial diseases: analysis of brain metabolic abnormalities and their possible diagnostic relevance. AJNR Am J Neuroradiol 2003;24:1958-66.

166. Cross JH, Connelly A, Gadian DG, et al. Clinical diversity of pyruvate dehydrogenase deficiency. Pediatr Neurol
1994;10:276-83.

167.Zand DJ, Simon EM, Pulitzer SB, et al. In vivo pyruvate detected by MR spectroscopy in neonatal pyruvate dehydrogease deficiency. AJNR Am J Neuroradiol 2003;24:1471-4.

168. Dallabona C, Abbink TE, Carrozzo R, et al. LYRM7 mutations cause a multifocal cavitating leukoencephalopathy with distinct MRI appearance. Brain 2016;139:782-94.

169. Lin DD, Crawford TO, Barker PB. Proton MR spectroscopy in the diagnostic evaluation of suspected mitochondrial disease. AJNR Am J Neuroradiol 2003;24:33-41.

170. Frahm J, Hanefeld F. Magnetic Resonance Spectroscopy and Imaging in Neurochemistry. In: Bachelard H. ed. Advances in Neurochemistry Vol. 8. New York and London: Plenum Press, 1997:371-5.

171. Rubio-Gozalbo ME, Heerschap A, Trijbels JMF, et al. Proton MR spectroscopy in a child with pyruvate dehydrogenase complex deficiency. Magn Reson Imaging 1999; 17:939-44.

172.Brockmann K, Bjornstad A, Dechent P, et al. Succinate in dystrophic white matter: a proton magnetic resonance spectroscopy finding characteristic for complex II deficiency. Ann Neurol 2002;52:38-46.

173. Cecil KM, Kos RS. Magnetic resonance spectroscopy and metabolic imaging in white matter diseases and pediatric disorders. Top Magn Reson Imaging 2006;17:275-93.

174. Bizzi A, Castelli G, Bugiani M, et al. Classification of childhood white matter disorders using proton MR spectroscopic imaging. AJNR Am J Neuroradiol 2008;29:1270-5.

175.Steenweg ME, Vanderver A, Blaser S, et al. Magnetic resonance imaging pattern recognition in hypomyelinating disorders. Brain 2010;133:2971-82.

176. Brockmann K, Dechent P, Wilken B, et al. Proton MRS profile of cerebral metabolic abnormalities in Krabbe disease. Neurology 2003;60:819-825.

177. Martin E, Capone A, Schneider J, et al. Absence of $\mathrm{N}$-acetylaspartate in the human brain: Impact on neurospectroscopy?. Ann Neurol 2001;49:518-21.

178. Stockler-Ipsiroglu S, van Karnebeek CD. Cerebral creatine deficiencies: a group of treatable intellectual developmental disorders. In: Seminars in neurology. New York: Thieme Medical Publishers, 2014:350-6.

179. Schulze A. Creatine deficiency syndromes. Mol Cell Biochem 2003;244:143-50.

180.Ensenauer R, Thiel T, Schwab KO, et al. Guanidinoacetate 
methyltransferase deficiency: differences of creatine uptake in human brain and muscle. Mol Genet Metab 2004;82:208-13.

181. Bizzi A, Bugiani M, Salomons GS. X-linked creatine deficiency syndrome: a novel mutation in creatine transporter gene SLC6A8. Ann Neurol 2002;52:227-31.

182. Otaduy MCG, Leite CC, Lacerda MTC, et al. Proton MR spectroscopy and imaging of a galactosemic patient before and after dietary treatment. AJNR Am J Neuroradiol 2006;27:204-7.

183. Wang ZJ, Berry GT, Dreha SF, et al. Proton magnetic resonance spectroscopy of brain metabolites in galactosemia. Ann Neurol 2001;50:266-9.

184. Moolenaar SH, Van der Knaap MS, Engelke UF, et al. In vivo and in vitro NMR spectroscopy reveal a putative novel inborn error involving polyol metabolism. NMR Biomed 2001;14:167-76.

185.van der Knaap MS, Wevers RA, Struys EA, et al. Leukoencephalopathy associated with a disturbance in the metabolism of polyols. Ann Neurol 1999;46:925-928.

186. Wilken B, Dechent P, Hanefeld F, et al. Proton MRS of a child with Sandhoff disease reveals elevated brain hexosamine. Eur J Paediatr Neurol 2008:12:56-60.

187. Franco LP, Anderson J, Okoh J, et al. Proton MR spectroscopy in hyperhomocysteinemia with elevated blood methionine levels. J Magn Reson Imaging 2006;23:404-7.

188. Foerster BR, Coklin LS, Petrou M, et al. Minimal hepatic encephalopathy in children: evaluation with proton MR spectroscopy. AJNR Am J Neuroradiol 2009;30:1610-3.

Cite this article as: Liserre R, Pinelli L, Gasparotti R. MR spectroscopy in pediatric neuroradiology. Transl Pediatr 2021;10(4):1169-1200. doi: 10.21037/tp-20-445
189. Weissenborn K, Ahl B, Fischer-Wasels D, et al. Correlations between magnetic resonance spectroscopy alterations and cerebral ammonia and glucose metabolism in cirrhotic patients with and without hepatic encephalopathy. Gut 2007;56:1736-42.

190. Rovira A, Alonso J, Cordoba J. MR imaging findings in hepatic encephalopathy. AJNR Am J Neuroradiol 2008;29:1612-21.

191.Alonso J, Córdoba J, Rovira A. Brain magnetic resonance in hepatic encephalopathy. Semin Ultrasound CT MR 2014;35:136-52.

192.Kreis R, Pfenninger J, Herschkowitz N, et al. In vivo proton magnetic resonance spectroscopy in a case of Reye's syndrome. Intensive Care Med 1995;21:266-9.

193. Isohanni P, Hakonen AH, Euro L, et al. POLG1 manifestations in childhood. Neurology 2011;76:811-5.

194. Iodice A, Ferrari S, Pinelli L, et al. A Case of AlpersHuttenlocher Syndrome Due to a New POLG1 Mutation with Rapid Onset of Partial Status Epilepticus: Serial Neuroradiological and Neurophysiological Evaluation. J Pediatr Neurol 2016;14:112-8.

195. Cameron FJ, Kean MJ, Wellard RM, et al. Insights into the acute cerebral metabolic changes associated with childhood diabetes. Diabet Med 2005;22:648-53.

196. Wootton-Gorges SL, Buonocore MH, Kuppermann N, et al. Detection of cerebral $\beta$-hydroxy butyrate, acetoacetate, and lactate on proton MR spectroscopy in children with diabetic ketoacidosis. AJNR Am J Neuroradiol 2005;26:1286-91. 
Acronyms and abbreviations in tables, figures, and figure legends (alphabetical order)

\section{Metabolites}

AAs, amino acids; Ala, alanine; Cho, tCho, total choline; $\mathrm{Cr}, \mathrm{Cr}_{1}$, creatine first peak; $\mathrm{Cr}_{2}$, creatine second peak; GAA, guanidinoacetate; Glc, glucose; Gln, glutamine; Glu, glutamate; $\alpha-\mathrm{Glx}, \mathrm{Glx}_{\mathrm{dd}}$, alpha-methine group of glutamate + glutamine; $\beta, \gamma$-Glx, $\mathrm{Glx}_{\mathrm{m} 1, \mathrm{~m} 2, \mathrm{~m} 3}$, beta, gamma-methylene groups of glutamate + glutamine; Glyc, glycine; $\mathrm{H}_{2} \mathrm{O}$, water peak; Lac, lactate; Lip, lipids; m-Ins, m-Ins 1 , Ins, Ins ${ }_{\mathrm{dd1}}$,dd2, myo-Inositol first peak; m-Ins ${ }_{2}$, myo-Inositol second peak; MM, macromolecules; NAA, $\mathrm{NAA}_{1}, \mathrm{~N}$-acetyl-aspartate first peak; $\mathrm{NAA}_{2}, \mathrm{~N}$-acetyl-aspartate second peak; $\mathrm{NAA}_{3}$, $\mathrm{N}$-acetyl-aspartate third peak; s-Ins, Scyllo, scyllo-Inositol; Tau, taurine; 2HG, 2-hydroxyglutarate.

\section{Other acronyms and abbreviations}

ADC, apparent diffusion coefficient; A.U., arbitrary units;
$\mathrm{CH}$, methine group; $\mathrm{CH}_{3}$, methyl group; CSI, chemical shift imaging; DNET, dysembryoplastic neuroepithelial tumor; DWI, diffusion-weighted imaging; FLAIR, fluid attenuated inversion recovery; HIE, hypoxic-ischemic encephalopathy; $\mathrm{H}^{1} \mathrm{MRS}$, hydrogen magnetic resonance spectroscopy; IDH, isocitrate dehydrogenase; LCModel, linear combination model; MRI, magnetic resonance imaging; ms, milliseconds; P, position; $\mathrm{MB}$, medulloblastoma; POLR3A, RNA polymerase III subunit A; ppm, parts per million; PRESS, Point-RESolved Spectroscopy; SHH, sonic hedgehog; STIR, short Tau inversion recovery; SVS, single voxel spectroscopy; T, tesla; TE, echo time; VOI, volume of interest; WHO, World Health Organization; WI, weighted Images; WM, white matter; yo, years old; $4 \mathrm{H}$, hypomyelination, hypogonadotropic hypogonadism and hypodontia. 